\title{
Calidad regulatoria en Perú: de la simplificación administrativa al análisis de impacto regulatorio en cámara lenta

\section{Eduardo Quintana SÁnchez}

Abogado por la Pontificia Universidad Católica del Perú. Master en Regulación de Servicios Públicos por la London School of

Economics and Political Science. Profesor de las Facultades de Derecho y Programas de Post Grado de la Pontificia Universidad Católica del Perú y de la Universidad del Pacífico.

SUMARIO:

I. Introducción.

II. Reforma Regulatoria: AIR y Simplificación Administrativa.

1. Análisis de Impacto Regulatorio - AIR.

2. Simplificación Administrativa —red tape-.

3. Calidad regulatoria: ¿AlR o simplificación administrativa?

III. Simplificación administrativa y AIR en Perú.

1. Simplificación administrativa en Perú.

2. ¿Programas de AIR en Perú?

2.1. $\quad A C B$ para proyectos de ley y regulaciones de inferior jerarquía.

2.2. Principios de AIR en la regulación de servicios públicos.

2.3. Evaluaciones ex post del impacto de las regulaciones sobre el acceso o permanencia en el mercado.

IV. Análisis de Calidad Regulatoria - ACR en Perú.

V. El Reglamento de AIR: un esfuerzo frágil para la reforma regulatoria integral.

VI. Una oportunidad perdida y una reforma regulatoria aún incompleta. 


\section{RESUMEN:}

En este artículo se revisa y discute la distinción equívoca que ha surgido en Perú —a nivel legal y conceptual — entre lo que se ha denominado análisis de calidad regulatoria, asociándolo con una herramienta de simplificación administrativa, y la llamada mejora de la calidad regulatoria a través, entre otros instrumentos, del Análisis de Impacto Regulatorio - AIR. Para ello, se describen los conceptos e iniciativas desarrolladas por la mejor práctica internacional sobre el AIR, como piedra angular para asegurar la calidad de las regulaciones sustantivas — regulación económica, social, etcétera-, y sobre las herramientas de simplificación administrativa para reducir cargas regulatorias, como medidas complementarias. Igualmente, se explica el extenso desarrollo que se ha dado en Perú a la simplificación administrativa, y cómo hace 5 años se lanzó el programa de Análisis de Calidad Regulatoria — ACR, pero reduciéndolo a una forma, más sofisticada, de simplificación administrativa. Asimismo, se explican las iniciativas dispersas y poco efectivas de AIR que hasta ahora se habían dado en nuestro país. Finalmente, se describe la nueva reglamentación del AIR como un esfuerzo frágil aún para implementar una reforma regulatoria integral. Como conclusiones relevantes se tiene que la reforma regulatoria peruana ha priorizado los mecanismos accesorios en vez de los sustantivos, el mandato para hacer exigible el AIR es frágil porque solo está plasmado en una norma de rango infra legal, y además las reglas más relevantes para hacerlo efectivo aún pueden retrasarse. Es decir, continúa siendo una reforma regulatoria incompleta, vulnerable, y concentrada en la simplificación administrativa. .

Palabras clave: Análisis de impacto regulatorio, calidad regulatoria, cargas administrativas, reforma regulatoria, AIR (RIA), simplificación administrativa.

\section{ABSTRACT:}

This paper reviews and discusses a wrong distinction that has arisen in Peru —at both legal and conceptual levels — between (i) the so-called regulatory quality analysis, even though it is only an additional administrative simplification tool, and (ii) the improvement of regulatory quality through several tools including regulatory impact assessment — RIA. With this aim, it describes the concepts and initiatives implemented by the best international practices concerning, on one hand RIA as a cornerstone to ensure the quality of substantive regulations - economic and social regulations - and on the other hand, administrative simplification tools to reduce red tape as complementary measures. Likewise, it explains the developments in administrative simplification in Peru, including the launching of the so-called regulatory quality analysis program 5 years ago, reducing it only to a - more sophisticated — administrative simplification tool. This paper describes also the scattered and ineffective initiatives on RIA that have been carried out in Peru, as well as the latest RIA regulation which is still a fragile effort to effectively implement an integral regulatory reform. In sum, Peruvian regulatory reform has prioritized ancillary mechanisms rather than substantive ones. The mandate to enforce RIA is weak because it has been only passed by a regulation rather than a law, and the approval of relevant provisions to make RIA effective may still be delayed. Therefore, regulatory reform is yet incomplete, vulnerable, and focused on administrative simplification.

Keywords: Administrative simplification, red tape, regulatory impact assessment, RIA, regulatory reform, regulatory quality.

\section{INTRODUCCIÓN}

¿A quién no le gusta tener cosas de calidad? La simple referencia a que algo es de calidad implica una valoración positiva. Usualmente se tiene disposición a invertir los recursos, sean pocos o muchos, en algo de mayor calidad. La información confusa sobre algo que es de calidad disgusta, se considera engañosa. En el caso de la calidad de la regulación o de la denominada calidad regulatoria sucede lo mismo.

El término regulación abarca las distintas formas en que el estado interviene en la vida de los privados y en la propia actuación de los agentes públicos, a través de normas generales o decisiones y actos particulares, referidos a aspectos simples y cotidianos o a ámbitos complejos y abstractos.

El estado regula cuando crea obligaciones como tener el Documento Nacional de Identidad vigente, presentar la partida de nacimiento para un trámite, llenar vía digital declaraciones periódicas sobre ingresos personales para efectos de pago de impuestos, cumplir requisitos y presentar documentos para obtener una licencia de funcionamiento para una empresa o para construir una planta industrial, generar registros detallados de información sobre las 
actividades económicas que realizan las empresas para ser remitidos a alguna autoridad, entre otros.

A estas exigencias, requisitos y trámites se les denomina cargas regulatorias, porque imponen costos en tiempo y dinero para las personas y empresas. Si no están bien pensadas, son redundantes o resultan desproporcionadas, darles cumplimiento puede ser inviable o invivible. Se convierte en lo que peyorativamente llamamos "pura burocracia".

Pero el estado también regula cuando permite que un abogado ejerza su profesión en todo el país bastando que tenga el registro vigente de alguno de los colegios de abogados existentes; cuando limita a 2 el número de operadores de servicios de transporte terrestre interprovincial autorizados para la ruta Lima - Huancayo; cuando cambia de $93 \%$ a $99 \%$ el estándar mínimo de concentración del oxígeno medicinal que deben adquirir los centros de salud; cuando establece una tasa de impuesto selectivo al consumo de $40 \%$ para el uso de combustibles con ciertos niveles de azufre; o cuando fija la tasa de interés legal.

Estas medidas crean derechos, establecen prohibiciones o restricciones, determinan reglas de actuación para las personas o empresas, o generan incentivos para promover determinados comportamientos deseados. Ellas definen situaciones en las que seguramente habrá beneficiados y perjudicados, que implicarán algunos costos de cumplimiento difíciles de identificar y valorar, cuya supervisión requerirá la inversión de recursos de distinto calibre por parte de las entidades públicas. Se trata de regulación sustantiva, cuya creación y mantenimiento en vigencia debe ser cuidadosamente estudiado.

Las intervenciones del estado son necesarias para generar equilibrios dentro de la sociedad y para contribuir al desarrollo, pero siempre que sean razonables, acotadas a lo mínimo para no limitar indebidamente la libertad individual, manteniéndose en todo lo posible como supletorias a la decisión o iniciativa privada, y en general asegurando que sean estrictamente proporcionales a los fines que buscan lograr.

La calidad del proceso de creación y mantenimiento en vigencia de las regulaciones se asegura cuidando que se logren sus objetivos al ADMINISTRATIVO menor costo posible para la sociedad. Esto se logra evaluando suficientemente sus impactos positivos y negativos, y escuchando también las posiciones de todos los interesados. No solo debe asegurarse la calidad de las regulaciones que establecen requisitos y trámites, sino sobre todo de aquellas que definen los aspectos sustantivos.

En esa línea, los esfuerzos por reducir y racionalizar las cargas administrativas se engloban dentro del concepto de simplificación administrativa, independientemente de los instrumentos que se utilicen, sean aprobaciones automáticas y silencios administrativos positivos o negativos, reglas de no duplicación de documentos o de reportes de información, métodos de cuantificación de los costos de cumplimiento, etcétera

De otro lado, los esfuerzos para asegurar que se creen regulaciones sustantivas que cumplan sus objetivos de manera efectiva y eficiente, esto es, sin generar costos exagerados respecto de los problemas que buscan resolver o de los fines que persiguen, se engloban bajo el nombre de evaluación o análisis de impacto regulatorio - AIR o RIA por las siglas del término en inglés-, independientemente del tipo de metodología que se utilice para medir y comparar las ventajas y desventajas de las medidas propuestas -análisis costo-beneficio, análisis costo-riesgo, análisis multicriterio, etcétera-. Esta evaluación siempre viene acompañada de mecanismos de consulta pública sistemática para escuchar a todos los interesados. De este modo, el AIR constituye una forma óptima y democrática de asegurar la calidad regulatoria.

Sin embargo, en Perú ha surgido una distinción equívoca - a nivel legal y conceptual- entre el análisis de calidad regulatoria asociado solo 
a la simplificación administrativa, y los instrumentos de mejora regulatoria que incluyen, entre otros, al AIR, como si este último estuviera al mismo nivel que la simplificación administrativa o aún peor como si tuviera una relevancia menor, cuando a nivel internacional es todo lo contrario.

En este trabajo se explica el contexto nacional en materia de simplificación administrativa y de AIR, se presenta y discute la distinción que ha surgido y por qué no tiene asidero, y cómo ha contribuido a que hasta ahora la reforma regulatoria en Perú siga incompleta, sea vulnerable, y esté concentrada aún en la simplificación administrativa.

\section{REFORMA REGULATORIA: AIR Y SIMPLIFI- CACIÓN ADMINISTRATIVA}

La búsqueda de la reducción de las cargas impuestas por la administración pública a los ciudadanos y en particular a la libre empresa surgió hace varias décadas atrás, pero el objetivo de racionalizar el quehacer normativo del estado se ha vuelto cada vez más ambicioso y sofisticado, encaminándose por las rutas del AIR, como sistema y/o proceso más sofisticado para lograr esa meta.

Ciertamente, en las iniciativas para tratar de conseguir que las regulaciones logren su objetivo al menor costo posible, ha primado el enfoque económico, pero con distintos niveles de protagonismo. Algunos países o jurisdicciones sustentan la viabilidad de la regulación a emitirse en los resultados de un análisis tipo costo-beneficio; otras se valen de la evaluación de los impactos de la regulación principalmente para informar de manera oportuna y suficiente a quienes deben aprobarla; y también están las que concentran la evaluación a ámbitos más acotados, por ejemplo limitando los alcances del análisis de impacto por la materia — solo impacto en costos de cumplimiento por los emprendedores o empresas- o por el tipo de normas — solo las exigencias y trámites administrativos excesivos-.

\section{Análisis de Impacto Regulatorio - AIR.}

El origen de las iniciativas antes mencionadas pueden rastrearse en decisiones de instancias administrativas o judiciales de revisión de medidas y exigencias impuestas por el estado a los administrados, como por ejemplo el Consejo de Estado Francés o la Corte Suprema de Estados Unidos, que para verificar si tales medidas o exigencias respondían efectivamente al interés público, exigían que las restricciones a la propiedad, los costos financieros o el costo social impuesto no superasen los beneficios esperados de la alternativa normativa escogida, o en todo caso que las autoridades demostraran que habían considerado razonablemente formas alternativas de regulación para escoger las menos restrictivas.'

No obstante, como se sabe, las primeras manifestaciones sistemáticas de esta forma de análisis de la regulación surgieron en 1981 durante el gobierno de Reagan en Estados Unidos, y en 1986 durante el gobierno de Thatcher en el Reino Unido.

Al respecto, mediante la Orden Ejecutiva 12291 de 1981 se estableció un conjunto de reglas para la creación de nueva regulación en Estados Unidos, que configuran el denominado análisis costo-beneficio, entre las que pueden señalarse:

a) Que se valorice monetariamente las diferentes ventajas y costos esperados de la medida, sean directos o indirectos, para los distintos posibles beneficiarios y afectados, incluyendo al propio estado, en el corto y mediano plazo;

b) Que se comparen los costos y beneficios y términos monetarios;

1. Jean-Bernard Auby y Thomas Perroud, Regulatory Impact Assessment Introduction, (Sevilla: Global Law Press, 2013), 22-24 y 26-28. 
c) Que no se adopten regulaciones salvo que sus beneficios potenciales estimados superen sus potenciales costos para la sociedad;

d) Que se adopten los objetivos de la regulación que maximicen el beneficio neto para la sociedad;

e) Que, entre varias alternativas para lograr un objetivo regulatorio, se escoja la que ocasione el menor costo neto para la sociedad; entre otras.

En 1993 se emitió la Orden Ejecutiva 12866 durante el gobierno de Clinton, haciendo algunos cambios en el énfasis del análisis para señalar, por ejemplo, que los beneficios esperados de las regulaciones debían justificar -ya no superar- sus costos, así como la relevancia de considerar también los impactos distributivos y de equidad de las medidas.

En el caso del Reino Unido, la primera iniciativa para impulsar el análisis del impacto de la regulación se dio en 1986, cuando se ordenó que todas las autoridades del gobierno debían evaluar el impacto de los proyectos normativos en los costos de cumplimiento de esas normas por las empresas, que luego se denominó análisis de costos de cumplimiento, incluyendo también la revisión periódica de las regulaciones para eliminar, simplificar o racionalizar las exigencias impuestas en las empresas.

Este enfoque fue sustituido en 1998 durante el gobierno de Blair, como parte de la Iniciativa de Mejora del Gobierno "Better Regulation", estableciéndose un sistema de evaluación de impacto regulatorio más integral, mediante etapas consecutivas para:
a) Definir el objetivo de la intervención regu- ladora propuesta,
b) Identificar las alternativas de regulación disponibles para conseguir ese objetivo,
c) Evaluar los costos y beneficios de cada al-

ternativa para los distintos agentes involucrados incluyendo al propio estado encargado de hacer cumplir la regulación,

d) Considerar los riesgos asociados a su aplicación,

e) Efectuar la consulta pública del caso para recoger opiniones y sugerencias de los in- ADMINISTRATIVO teresados, $y$

f) Escoger la alternativa de intervención reguladora más apropiada teniendo todos esos elementos de juicio a su alcance, o preferir la opción de no regular. ${ }^{2}$

Si bien este tipo de evaluación de impacto en el Reino Unido sigue teniendo un enfoque económico, no implica que la aprobación de la regulación dependa de que los beneficios superen los costos identificados, como fue originalmente en Estados Unidos.

En paralelo, bajo su denominado programa de "reforma regulatoria", la Organización para la Cooperación y el Desarrollo Económico OCDE, promovió durante la década de 1990 la implementación de sistemas de AIR — con las mismas características del descrito para Reino Unido en 1998-, como una segunda etapa luego de la ola de desregulación de la economía que impactó en diversos países miembros de esa entidad. Así, la adopción del AIR se materializó primero en los países más desarrollados y paulatinamente y con distinto alcance en países en vías de desarrollo.

El término reforma regulatoria es utilizado por la OCDE

"para referirse a cambios que mejoran la calidad regulatoria, es decir, que mejoran el desempeño, la rentabilidad o la calidad de las regulaciones y las formalidades gubernamentales relacionadas. La reforma puede significar la revisión de una sola regulación, la desarticulación y reconstrucción de todo un régimen regulatorio y sus instituciones, $o$ la mejora de los procesos para hacer regula- 
ciones y gestionar la reforma" — subrayado añadido-3. ${ }^{3}$

Para tales efectos, la OCDE distinguió tres grandes categorías de regulaciones nacidas del aparato estatal en todo o en parte que son materia de la reforma regulatoria:

a) Regulaciones económicas, a través de las cuales se interviene en las decisiones de los agentes que participan en los mercados, como los precios que pueden fijar o la posibilidad que tienen de entrar al mercado. La reforma de este tipo de regulaciones busca incrementar la eficiencia económica y la competencia, a través de medidas de desregulación, de reducción de barreras de entrada al mercado y a la innovación, etcétera.

Considérese, por ejemplo, normas que establecen el número máximo de proveedores del servicio de taxi habilitados en una ciudad, un listado de precios máximos que pueden cobrar los notarios por sus distintos servicios, la limitación temporal de ingreso al mercado de empresas que producen electricidad con ciertas tecnologías, el establecimiento de horarios máximos y días habilitados para el funcionamiento de centros comerciales, la modificación de la zonificación de un área considerada industrial a comercial.

b) Regulaciones sociales, mediante las que se busca objetivos vinculados con la protección del medio ambiente, de la salud y seguridad, así como la cohesión social. En este rubro la reforma busca verificar la necesidad e idoneidad de las medidas aplicadas para conseguir esos fines, introduciendo en lo posible incentivos de mercado y enfoques basados en el logro más efectivo y simple de los objetivos a un menor costo.

Por ejemplo, se refieren a normas sobre niveles máximos de emisiones para actividades industriales que utilicen determinado combustible, obligaciones sobre rotulado en productos alimenticios de consumo masivo, medidas que incrementan las condiciones de seguridad ocupacional en actividades de extracción minera, protocolos sanitarios para conducir establecimientos de venta de alimentos como restaurantes, etc.

c) Trámites y procedimientos administrativos, que suelen calificarse como "trámites burocráticos" —en inglés se utiliza el término red tape para referirse a ellos-, a través de los cuales el estado recopila información de los administrados o define situaciones jurídicas individuales para ellos en el mercado. La reforma en este ámbito busca eliminar y/o simplificar los requisitos, así como mejorar la transparencia.

Algunos ejemplos hipotéticos podrían ser los requisitos para tramitar una licencia de construcción de una planta de harina de pescado, el trámite para obtener autorización de colocación de publicidad en la vía pública, las obligaciones de reporte semanal de transacciones con medios de pago electrónico por tipo de establecimiento, la obligación de registro en línea de atenciones a pacientes con dolencias relacionadas con enfermedades tropicales, y similares.

Como señalaba la OCDE en 1997, la mejora de la calidad regulatoria se concentraba en optimizar

"la capacidad de los gobiernos para actuar de manera efectiva al menor costo dentro de

3. Organisation for Economic Cooperation and Development, Report on Regulatory Reform: Synthesis (Paris: OECD Publishing, 1997), 6, https://www.oecd.org/gov/regulatory-policy/2391768.pdf. Traducción libre del siguiente texto: "Regulatory reform is used in the OECD work to refer to changes that improve regulatory quality, that is, enhance the performance, cost-effectiveness, or legal quality of regulations and related government formalities. Reform can mean revision of a single regulation, the scrapping and rebuilding of an entire regulatory regime and its institutions, or improvement of processes for making regulations and managing reform". 
mercados innovadores, competitivos y globales. La reforma se basa en eliminar las reglamentaciones y las formalidades obsoletas o ineficaces; en la racionalización y simplificación de las que sean necesarias; en el uso de una gama más amplia de incentivos de mercado y enfoques regulatorios internacionales más flexibles; y en la introducción de una mayor disciplina, coordinación y transparencia dentro de los procesos regulatorios". ${ }^{4}$

Pero el enfoque de la reforma regulatoria fue evolucionando y sofisticándose rápidamente, y en 2002 la OCDE reportaba que sus miembros habían ido migrando rápidamente a la concepción más sofisticada de gestión regulatoria. Esto significaba, por ejemplo, pasar de preguntarse qué regulación se debía eliminar -lo que ponía énfasis en la simplificación de los trámites y procedimientos administrativos-, a implementar herramientas para optimizar el proceso de creación normativa y vigilar su funcionamiento eficaz, es decir, herramientas de AIR.

Si bien los esfuerzos se concentraron primero en identificar regulaciones inadecuadas, eliminar exigencias regulatorias excesivas y promover reformas específicas, paulatinamente la reforma regulatoria fue tomando un lugar más preponderante, a través de su reconocimiento expreso como una política de gobierno, con metas específicas y mecanismos de evaluación como el AIR con metodologías de análisis costo-beneficio y/o costo-efectividad, y el uso de mecanismos de consulta, así como asignando la responsabilidad por el programa de reforma a determinados ministros y entidades gubernamentales. $^{5}$
Sin perjuicio de lo anterior, la OCDE verificaba que la evaluación de impactos de la regulación se había dado con distinto alcance, pues algunos países aplicaban el AIR completo, considerando la definición escrupulosa de costos y beneficios de distintas alternativas; mientras otros evaluaban principalmente los impactos ADMINISTRATIVO para las empresas; y algunos se concentraban más en la reducción de cargas administrativas y de tramitación —red tape-. No obstante, la OCDE planteaba que la evaluación de impactos debía conceptualizarse como una herramienta para examinar sistemática y consistentemente los efectos potenciales de la regulación y comunicar los resultados a los encargados de aprobarla. $^{6}$

Ciertamente, aún hay debate sobre el método para evaluar las ventajas y desventajas potenciales de la regulación, es decir, si conviene utilizar la metodología de costo-beneficio plena, pues ella exige una cuantificación monetaria de todos los impactos, incluyendo bienes que no están en el mercado como vida o salud, en el corto y largo plazo, en base a parámetros de disponibilidad de pago. Se discute también que con esta óptica pueda perderse de vista las diferencias reales en distribución de ingresos que existen en las sociedades -impactos distributivos - y cómo incorporar esa variable en el análisis. Por ello, ahora se trabaja con niveles intermedios de exigencia de cuantificación de impactos, enfatizando en aspectos como la efectividad o la coherencia de las normas con los objetivos que se buscan, o en determinados grupos de interés. Se ha acuñado así el denominado análisis multicriterio. Asimismo, se considera como alternativa una combinación de

4. Ibíd, p. 9. Traducción libre del siguiente texto: "The focus of reform is on improving regulatory quality, a multi-faceted economic and legal concept aimed at improving the capacity of governments to act effectively at lowest cost within innovative, competitive, and global markets. Reform is based on screening out regulations and formalities that are outdated or ineffective; streamlining and simplification of those that are needed; use of a wider range of market incentives and more flexible and international regulatory approaches; and introduction of greater discipline, co-ordination, and transparency within regulatory processes".

5. Organisation for Economic Co-operation and Development, Regulatory Policies in OECD Countries: from Interventionism to Regulatory Governance (Paris: OECD Publishing, 2002), 16 y 23.

6. Ibíd, 44-45. 
evaluación de impacto ex ante no tan exhaustiva y revisión ex post de efectividad.?

Asimismo, se proponen métodos simplificados de evaluación de impactos. En primer lugar, definir mejor el -o los- problemas específicos que se buscan solucionar con la regulación propuesta, de modo que la revisión de impactos se simplifique desde el origen. Segundo, se definan anticipadamente plantillas de preguntas clave a ser respondidas para ir identificando los impactos más serios. Tercero, se busque considerar preferentemente alternativas de regulación menos intervencionistas, guardando las más intrusivas - controles de precios, cuota de producción, estándares de calidad uniformizada obligatorios, limitaciones a la entrada al mercado, etcétera - para los problemas más complejos. Cuarto, se confíe más en la consulta pública para definir la razonabilidad de las soluciones regulatorias propuestas. ${ }^{8}$

Lo relevante de trabajar las propuestas regulatorias con el AIR es que hace concreta la lógica de la proporcionalidad de la intervención reguladora. Permite tener visibilidad de los impactos en términos de ventajas y desventajas bien identificadas, aun cuando no se utilice una metodología de costo-beneficio plena, porque permite un juicio valorativo sustentado en la factibilidad y costo de las soluciones regulatorias. En otras palabras, un método que refleje la esencia del costo-beneficio, basado en la información que pueda recolectarse sobre los impactos, es una fuerte importante para entender los méritos de las medidas propuestas y apoyar la toma de decisiones. Además, la experiencia demuestra que, con el tiempo, las entidades se van sofisticando en la aplicación del AIR. ${ }^{9}$

En ese sentido, la OCDE ha puesto de relieve que: "La experiencia demuestra que la contribución más importante del AIR para la calidad de las decisiones no está en la precisión de los cálculos, sino en la acción de analizar y cuestionar, comprender los impactos en el mundo real y explorar los presupuestos asumidos 110 — subrayado añadido-.

Pero por sobre todo, es indiscutible en la actualidad que el AIR ya no solo es un método para darle racionalidad a la regulación, sino que se constituye en una nueva manera de definir y construir el interés público que se busca con la regulación. Así, se ha planteado con muy buen criterio que un sistema de AIR:

"ejemplifica una concepción cambiante del interés público. El AIR muestra que el interés público ya no surge de la voluntad de la administración, sino de un equilibrio de costos $y$ beneficios. El interés público ya no es algo que la administración pueda declarar unilateralmente; debe estar justificado, construi$d^{\prime \prime 11}$ — subrayado añadido-.

7. Andrea Renda, "Cost-Benefit Analysis and EU Policy. Limits and Opportunities", en The EU Better Regulation Agenda. A Critical Assessment. Eds. Sacha Garben e Inge Govaere (Oxford: Hart Publishing, 2018), 49-62.

8. Scott Jacobs, "Towards a simpler and Practical Approach", en Handbook of Regulatory Impact Assessment. Eds. Claire Dunlop y Claudio Radaelli (Cheltenham: Edward Elgar Publishing, 2016), 78-90.

9. Organisation for Economic Co-operation and Development, Regulatory Policies... 129.

10. Ibíd, 47. Traducción libre del siguiente texto: "Far from being a technocratic tool that can be simply "added on" to the decision-making system by policy directive, it is a method for transforming the view of what is appropriate action, indeed, what is the proper role of the state. Experience makes clear that RIA's most important contribution to the quality of decisions is not the precision of the calculations used, but the action of analysing - questioning, understanding real-world impacts, and exploring assumptions".

11. Auby y Perroud, Regulatory Impact Assessment, 22-23. Traducción libre del siguiente texto: "RIA exemplifies this changing conception of the public interest. First RIA shows that the public interests no longer stems from the will of the administration but from a balance of costs and benefits. The public interest is no longer something the administration can declare unilaterally; it must be justified, constructed". 


\section{Simplificación administrativa -red tape-}

Sin perjuicio de la relevancia y efectividad de los programas de AIR que la OCDE promueve decididamente, esta entidad también reconoce los esfuerzos que se han desplegado en sus países miembros para lograr una mayor simplificación administrativa ante la constatación de que diversos costos regulatorios se trasladaban a los ciudadanos y empresas a través de formularios a completar, requisitos para obtener permisos, u obligaciones de reporte de información. Esto retrasa el inicio de actividades económicas, fuerza a los privados a desviar recursos destinados a inversiones productivas para cumplir con las exigencias administrativas, reduce la innovación y la creación de empleo.

En ese sentido, en 2003 la OCDE reportaba que los programas de simplificación administrativa buscaban eliminar disposiciones obsoletas o contradictorias e introducir herramientas para reducir y medir el impacto de las regulaciones administrativas. En particular, se buscaba mejorar la gestión gubernamental de los requisitos de información impuestos a las empresas, la ciudadanía y el sector público en general. ${ }^{12}$

Entre los casos de estudio relevantes se mencionaba por ejemplo la Paper Reduction Act emitida en los Estados Unidos en 1980, que contemplaba un programa centralizado para analizar y reducir las exigencias de recopilación de información impuestas. Esta norma obligó a las agencias federales a solicitar la aprobación de la Office of Management and Budget $-O M B$, antes de establecer cualquier medida de recopilación de información. La $\mathrm{OMB}$ evaluaba la solicitud sopesando la utilidad práctica de la información para la agencia frente a la carga que se impone al público. La agencia debía demostrar que exigir esa información era la forma más eficiente de obtener- la, que la información era necesaria para el adecuado desempeño de sus funciones, y que no se estaba duplicando la información que la agencia ya tenía.

Asimismo, se comentaba el método MISTRAL desarrollado en la década de 1990 en Holanda ADMINISTRATIVo para medir los costos de las cargas administrativas. El método funcionaba en tres etapas: (i) individualizar y definir todas las transferencias de información de una empresa a una autoridad - sea a través de un documento, una llamada telefónica, una inspección, etcétera-; (ii) determinar el tiempo que implica cada transferencia de información y la calificación profesional de la persona que la realiza, así como su salario por hora; y (iii) estimar los costos, tanto en dinero como en tiempo. Sin perjuicio de ello, se reconocía que la primera vez que se utilizaba este método era bastante laborioso, porque implica definir el costo base de todas las cargas regulatorias. ${ }^{13}$

El uso de este método de estimación de los costos de las cargas regulatorias se ha extendido notoriamente en el mundo, como el Modelo Costo Estándar. Según este modelo, la regulación ocasiona diversos costos para los individuos y empresas, como costos financieros - por ejemplo, el derecho pagado para la obtención de una autorización o licencia-y costos de cumplimiento. A su vez, los costos de cumplimiento pueden ser costos sustantivos - por ejemplo, el despliegue de instalaciones de producción que cumplan las condiciones de seguridad y salud en el trabajo ordenadas por las normas laborales-, o costos administrativos - como sería la remisión a una autoridad de un reporte anual de cumplimiento de las referidas condiciones laborales-. Dentro de los costos administrativos están las cargas administrativas, que los individuos o empresas deben cumplir simplemente porque es un requisito impuesto por la regulación.

12. Organisation for Economic Co-operation and Development, From Red Tape to Smart Tape: Administrative Simplification in OECD Countries (Paris: OECD Publishing, 2003), 14-16.

13. Ibíd, 35 y 45 . 
El Modelo de Costo Estándar solo tiene por finalidad medir las cargas administrativas, sin evaluar si la regulación sustantiva es razonable o no. Lo que se busca es conocer el costo -en tiempo y dinero- asociado con una obligación específica, considerando la cantidad de veces que debe cumplirse dicha obligación anualmente..$^{14}$

Sin embargo, debe señalarse que aun cuando los esfuerzos de simplificación administrativa son importantes, la propia OCDE resalta de modo explícito que:

"Los programas de simplificación administrativa, si bien potencialmente importantes y vinculados al logro de valores fundamentales de gobernanza, no pueden sustituir a un programa de calidad regulatoria riguroso. Las materias de calidad regulatoria son más amplias que las abordadas mediante programas de simplificación administrativa. Además, a medida que los programas de calidad regulatoria se vuelven más completos en su diseño e implementación, es posible que en cierta medida la necesidad de programas de simplificación administrativa disminuya. (...). Siendo el AIR un enfoque más sistemático debe preferirse al carácter esencialmente ad hoc de la mayoría de las iniciativas de simplificación $^{\prime 15}$ - subrayado agregado-.

\section{Calidad regulatoria: ¿AIR o simplificación administrativa?}

De todo lo explicado previamente, se entiende que el AIR es la forma más utilizada en la actualidad para lograr que las regulaciones consigan sus objetivos al menor costo social posible. Además, su utilización ha cambiado la manera como se define lo que es de interés público, pues con sistemas de ese tipo las autoridades no pueden definir la conveniencia de la intervención reguladora a su solo criterio, sino que deben demostrar de modo transparente que dicha intervención es necesaria y es costo-efectiva.

Los sistemas de AIR desplegados tienen siempre un enfoque económico de evaluación, pero sus alcances pueden ser distintos. Algunos países adoptan un sistema integral, que requiere aplicar el AIR no solo para la creación de las principales normas sino también para evaluar ex post su funcionamiento efectivo; mientras otros tienen sistemas menos ambiciosos, limitados a la evaluación de impacto en ciertos rubros - costos de cumplimiento para las empresas grandes, medianas y pequeñas - o solo para cierto tipo de regulación -exigencias y trámites burocráticos o red tape-.

Dentro de los sistemas integrales, el uso del AIR puede ser concluyente para la creación de normas - aprobar solo las normas cuyos costos no excedan los beneficios esperados-, o servir para que la creación de normas sea una decisión suficientemente informada sobre sus posibles impactos -incluso si sus costos pudieran exceder los beneficios esperados-. Asimismo, se puede unificar el sistema asignando responsabilidades específicas a determinados ministerios o autoridades, de modo que conduzcan el sistema, aseguren su efectividad y rindan cuentas al respecto, o sino mantener las iniciativas de evaluación de impacto con carácter frac-

14. Al respecto ver: SCM Network, International Standard Cost Model: Measuring and reducing administrative burdens for businesses, 6-9, acceso el 19 de diciembre de 2020, https://www.oecd.org/regreform/regulatory-policy/34227698.pdf

15. OCDE, From Red Tape to Smart Tape... p 66. Traducción libre del siguiente texto: "Administrative simplification programmes, while potentially important and linked to the achievement of a number of core governance values, cannot be a substitute for a rigorous regulatory quality programme. The issues of regulatory quality are broader than those dealt with via administrative simplification programmes. Moreover, as regulatory quality programmes become more comprehensive in their design and implementation, it can be speculated that the need for administrative simplification programmes may, to some extent, diminish. (...). RIA being a more systematic approach must be preferred to the essentially ad hoc character of most simplification initiatives". 
cionado o según se vayan implementando por sectores.

Los programas de simplificación administrativa son parte de la agenda de reforma regulatoria y han sido aplicados a conciencia en diversos países, incluyendo (i) el uso de herramientas sofisticadas para la cuantificación de sobrecostos, (ii) medidas rigurosas para limitar la creación de nuevos trámites y cargas administrativas o forzar su desaparición, y (iii) el despliegue de una articulación centralizada para darle organicidad.

Sin embargo, está muy claro que cualquier programa de simplificación administrativa, por más riguroso y sofisticado que sea, es solo un ámbito de la reforma regulatoria, introduce racionalidad en la parte adjetiva de los sistemas regulatorios - los trámites y las cargas burocráticas-, pero no se compara ni menos aún sustituye un programa de AIR, que se ocupa de la parte sustantiva de los sistemas regulatorios, esto es, de la medidas —regulación económica, regulación social u otras equivalentes-que más sustancia e impacto tienen en cuanto a innovación, competitividad, creación de empleo, y bienestar de la sociedad en general.

\section{SIMPLIFICACIÓN ADMINISTRATIVA Y AIR EN PERÚ}

La agenda de reforma regulatoria en Perú ha sido dispersa, esporádica, y parcial. Han pasado tres décadas y en vez de apostar por un programa integral de AIR cuando se lanzó el programa de Análisis de Calidad Regulatoria - ACR, el año 2016, se optó por priorizar y concentrarse nuevamente en la simplificación administrativa.

En efecto, desde 1989 se ha ido saltando de programas de simplificación administrativa, a la introducción de la exigencia de análisis costo beneficio para crear leyes, a medidas de revisión ex-post de la racionalidad de ciertas regulaciones, a la introducción de tímidos principios de análisis costo-beneficio o costo-efectividad para crear regulaciones de servicios públicos, al establecimiento de reglas ADMINISTRATIVO de mejora para la producción normativa del Ejecutivo, y más recientemente a la emisión de lineamientos más definidos de evaluación de impacto regulatorio en servicios públicos, a impulsar un nuevo programa de simplificación administrativa bajo la llamativa denominación de Análisis de Calidad Regulatoria, y por último a una reglamentación de AIR solo a nivel de lineamientos y endeble aún.

A continuación, se describen todas las iniciativas previas al programa de ACR y a la reglamentación del AIR, que se comentarán y analizarán con más detalle en las siguientes secciones.

\section{Simplificación administrativa en Perú. ${ }^{16}$}

En 1989 se implementó el primer programa de simplificación administrativa en Perú, con la emisión de la Ley 25035, Ley de Simplificación Administrativa. Con esta norma se buscó sujetar a todas las entidades de la Administración Pública a principios y reglas de actuación que facilitaran la relación del ciudadano con el estado. Entre estos principios de actuación se encontraba, por ejemplo, la eliminación de exigencias y formalidades cuando los costos económicos que impusieran sobre la sociedad excedieran los beneficios que le reportaban, lo que implicaba eliminar exigencias de presentar documentos con información que ya tenía la entidad, así como el pago de derechos que excedieran el costo de producción de documentos - por ejemplo, documentos de identidad o pasaportes-. También se incorporó

16. Esta sección considera las descripciones del marco legal contenidas en los siguientes documentos: Contraloría General de la República, Mejora Regulatoria y Simplificación de Procedimientos Administrativos que Afectan la Inversión (Lima: Contraloría General de la República, 2016); William Muñoz, Perú: La Simplificación Administrativa en el Marco del Proceso de Modernización del Estado. Reformas de Trámites Empresariales (Lima: Universidad Católica Sedes Sapientiae, 2011); y Secretaría de Gestión Pública de la Presidencia del Consejo de Ministros, Política y Plan Nacional de Simplificación Administrativa (Lima: Secretaría de Gestión Pública de la Presidencia del Consejo de Ministros, 2010). 
la regla de presunción de veracidad para que la Administración Pública asuma que la información proporcionada por los ciudadanos era verdadera, sin perjuicio de la fiscalización posterior correspondiente.

Este fue un primer paso relevante hacia la modernización de los procedimientos y trámites administrativos, así como de reducción de exigencias exageradas impuestas por el estado al público en general.

En 1991 se dictó otra norma relevante en materia de simplificación administrativa, el Decreto Legislativo 757, Ley Marco para el Crecimiento de la Inversión Privada. Este decreto no solo dispuso que los trámites o requisitos administrativos solo puedan crearse mediante las normas de mayor jerarquía según el ámbito de gobierno - es decir, decreto supremo, decreto ejecutivo regional u ordenanza municipal-, sino que también ordenó que todos los organismos públicos unificaran, redujeran y simplificaran drásticamente los procedimientos y trámites administrativos bajo su competencia. También se introdujo el denominado Texto Único de Procedimientos Administrativos - TUPA, mediante el cual cada entidad debía compilar y actualizar anualmente todos los procedimientos que le correspondan, clasificándolos según fueran de aprobación automática, de evaluación previa con silencio administrativo positivo o negativo, o de aprobación expresa. Se dispuso además que las entidades estaban prohibidas de exigir cualquier trámite y requisito no consignado en su respectivo TUPA.

Esta norma marcó un hito en cuanto a la búsqueda de organizar y hacer más transparente la actuación del estado frente a los ciudadanos a través de los TUPA, que se utilizan hasta la actualidad. Con ello también se buscaba racionalizar las exigencias impuestas por la administración, a través de los mecanismos de aprobación automática y silencios administrativos. No obstante, se ha señalado que los TUPA no eliminaron la posibilidad de que las cargas se mantuvieran o incrementaran: "Sin embargo, otra vía quedó abierta; la obligación de revisión y publicación anual, puede ser utilizada para introducir modificaciones y acrecentar los trámites y tarifas, por lo que la percepción general es, más bien, que la complejidad de trámites y procedimientos ha sido aumentada con el tiempo".17

También debe mencionarse como parte de las medidas para impulsar la simplificación administrativa, la incorporación dentro del Instituto Nacional de Defensa de la Competencia y de la Protección de la Propiedad Intelectual INDECOPI, mediante Decreto Ley 25868, de la Comisión de Simplificación del Acceso y Salida del Mercado - que más adelante pasaría a denominarse Comisión de Eliminación de Barreras Burocráticas-. Esta Comisión se creó para conocer e inaplicar los actos y disposiciones de las entidades de la Administración Pública que impongan barreras burocráticas que impidan u obstaculicen ilegal o irracionalmente el acceso o permanencia de los agentes económicos en el mercado, así como velar por el cumplimiento de las disposiciones sobre simplificación administrativa y los TUPA.

Más adelante, en el año 2001, a través de la Ley 27444, Ley del Procedimiento Administrativo General —LPAG, se dejó sin efecto todas las reglas de simplificación administrativa antes señaladas, siendo incorporadas y ampliadas en esta ley. Con esta ley se unificó el sistema de simplificación administrativa, manteniendo la sistematización de procedimientos a través del TUPA de cada entidad pública, así como la clasificación de procedimientos según fueran de aprobación automática, de fiscalización posterior con verificación de oficio de los documentos proporcionados, de evaluación previa con silencio positivo o negativo.

17. Fernando Paredes, Simplificación Administrativa: Enfoque y Líneas de Trabajo en Materia Legislativa (Lima: Centro de Investigación Parlamentaria, 2005), 6. Ver: http://www4.congreso.gob.pe/historico/cip/centro_doc/ivirtuales/ simplificacion_administrativa.pdf (visitada 21 de diciembre de 2020). 
Asimismo, se contemplaron una serie de principios generales para la actuación del estado con una marcada lógica simplificadora —artículo IV—, mediante reglas que ordenan, entre otros: (i) trámites sencillos, eliminando cualquier complejidad innecesaria; (ii) requisitos similares para trámites similares, sin que se vuelvan generales las excepciones; (iii) presumir la veracidad de documentos y declaraciones; (iv) dotar a los trámites de la mayor celeridad posible; (v) interpretar las normas en favor de las pretensiones de los administrados para que sus intereses no sean afectados por exigencias formales subsanables; (vi) hacer prevalecer la finalidad del procedimiento sobre las formalidades no esenciales; (vii) brindar las condiciones para acceder a la información que tiene la administración; (viii) fiscalizar posteriormente, vigilando por el cumplimiento de la normatividad sustantiva.

La norma también señala criterios para que la administración diseñe correctamente sus procedimientos administrativos, con exigencias razonables según su objetivo y considerando sus costos y beneficios, en particular relativas a la documentación que puede solicitarse a los administrados y la que no puede requerirse, e incluso teniendo en cuenta la real capacidad de la administración para procesar la información exigida - artículo 39-. Asimismo, se establece la competencia de la Presidencia del Consejo de Ministros -PCM, y del INDECOPI para supervisar y fiscalizar las obligaciones de la administración para crear procedimientos administrativos - artículo 48-.

Como uno de los ejemplos de la acción simplificadora de la PCM puede mencionarse la Mesa Nacional de Simplificación de Trámites Municipales para Empresas - INTERMESA, constituida a inicios del 2006. Esta iniciativa de trabajo cooperativo público-privado generó mecanismos como Tramifácil, para concentrar esfuerzos en la mejora del desempeño de los gobiernos locales en la aprobación de licencias de funcionamiento y construcción.
Posteriormente, la Ley 29158, Ley Orgánica del Poder Ejecutivo, emitida en el año 2007, creó el Sistema Administrativo de Modernización de la Gestión Pública, en el que se incluye el sistema de simplificación administrativa bajo la rectoría de la Secretaría de Gestión Pública — SGP, de la PCM —artículo 46-. También en el 2007 se ADMINISTRATIVO emitió la Ley 29060, Ley del Silencio Administrativo, que contempla un mecanismo para justificar ante la SGP la creación de procedimientos administrativos y la fijación de los derechos de tramitación correspondientes, y además señala que corresponde a la SGP orientar a todas las entidades públicas en la elaboración y aprobación de sus TUPA. Más específicamente, en el Reglamento de Organización y Funciones de la PCM —Decreto Supremo № 063-2007-PCMse faculta a la SGP para identificar la duplicidad de funciones o de procedimientos administrativos en las entidades y proponer medidas necesarias para su corrección, así como para asesorar a las entidades en materia de simplificación administrativa, y evaluar los procesos de simplificación administrativa en relación con Ios TUPA.

Pese a todos los esfuerzos desplegados hasta ese momento, el resultado aún estaba lejos de ser óptimo en cuanto a simplificación, por ejemplo a través de los TUPA, señalándose que "(...) como refiere INDECOPI, el 51\% de las demandas por trabas y sobrecostos son aún contra las municipalidades, y al 11 de enero del 2010 solo el 25\% de las municipalidades distritales habían presentado la sustentación legal y técnica del TUPA. Es decir, queda aún mucho trecho por recorrer en la tarea de la simplificación administrativa".18

Con el ánimo de profundizar la reforma en esta materia se aprobó mediante Decreto Supremo No 025-2010-PCM la Política Nacional de Simplificación Administrativa propuesta por la SGP de la PCM, como política nacional de obligatorio cumplimiento para las entidades del sector público, y poco después también se probó el Plan Nacional de Simplificación Administrativa a través de la Resolución Ministerial № 228-2010-PCM, 
el mismo que contiene las acciones necesarias, metas, indicadores, plazos y entidades públicas responsables para la implementación de la referida política. El objetivo general de estas disposiciones son la mejora de la calidad, la eficiencia y la oportunidad de los procedimientos y servicios administrativos que la ciudadanía realiza ante la administración pública. Para tales efectos se "concibe la simplificación administrativa como la eliminación de las exigencias y formalidades innecesarias en los trámites que realizan los administrados ante las distintas entidades públicas. ${ }^{\text {"19 }}$

Luego se aprobó en sustitución la Política Nacional de Modernización de la Gestión Pública al 2021 —PNMGP, mediante el Decreto Supremo No 004-2013-PCM, y acto seguido el Plan Nacional de Simplificación Administrativa 2013 -2016 a través de la Resolución Ministerial № 048-2013-PCM. Los cuatro objetivos estratégicos de este Plan fueron: (i) promover la implementación de los procesos de simplificación administrativa orientada a generar resultados e impactos positivos para todos los ciudadanos; (ii) promover la incorporación progresiva de tecnologías de la información y de la comunicación como una estrategia para brindar servicios y trámites de calidad de los ciudadanos y empresas; (iii) desarrollar un Modelo de Atención al Ciudadano; y (iv) fortalecer el proceso de simplificación administrativa.

Entre las normas de relevancia que se emitieron en años posteriores sobre este tema, se encuentra la Ley 30230 -2014-, Ley que establece Medidas Tributarias, Simplificación de Procedimientos y Permisos para la Promoción y Dinamización de la Inversión en el País. Con ella se dispuso que toda tasa cobrada sin estar prevista en el TUPA de la entidad era un pago indebido y calificaba como una barrera burocrática ilegal que podía ser inaplicada por el INDECOPI. Asimismo, mediante el Decreto Legislativo 1203 - 2015 - se creó el Sistema Único de Trá- mites — SUT, bajo administración de la SGP de la PCM, como herramienta para registrar todos los TUPA de modo que además de ser un repositorio contribuyera a simplificar y estandarizar su producción. Igualmente, a través del Decreto Legislativo 1211 -2015—, se aprobó medidas para la implementación de servicios públicos integrados a través de ventanillas únicas de atención al público y ordenando el intercambio de información entre entidades, privilegiando el uso de medios electrónicos.

Todas las normas y medidas antes descritas dan cuenta de más de 25 años de implementación de programas y medidas de simplificación administrativa en nuestro país. En el 2016 la OCDE hizo un estudio de diagnóstico de la política regulatoria en Perú y en el ámbito de la simplificación administrativa identificó ciertas falencias e hizo algunas recomendaciones que mostraban que aún era necesario seguir avanzando con la reforma. Así, por ejemplo, la OCDE recomendó:

\begin{abstract}
"Realizar una medición de las cargas administrativas que generan los trámites y obligaciones de información de los mismos. Como alternativa a una línea base completa, se puede medir a los trámites asociados a las actividades económicas más importantes o los sectores prioritarios, lo cual permitiría enfocar los esfuerzos de simplificación administrativa en objetivos concretos". 20
\end{abstract}

Al finalizar el 2016 se emitió un conjunto de normas con contenidos asociados a las recomendaciones de la OCDE. De un lado, mediante el Decreto Legislativo 1256 se aprobó la Ley de Eliminación de Barreras Burocráticas, reforzando considerablemente al INDECOPI para dejar sin efecto disposiciones de la administración que generen barreras burocráticas ilegales o irracionales, dar cumplimiento a las normas de simplificación administrativa, y sancionar a la administración por incumplimientos.

19. Secretaría de Gestión Pública de la PCM, Política y Plan Nacional de Simplificación Administrativa, 34.

20. Organización para la Cooperación y Desarrollo Económicos, Política Regulatoria en el Perú. Uniendo el Marco para la Calidad Regulatoria: Aspectos Clave (París: OECD Publishing, 2016), 18. 
De otro lado, a través del Decreto Legislativo 1272 se introdujeron diversas modificaciones a la LPAG, vinculadas muchas de ellas con el objetivo de simplificación. Así, por ejemplo, se incorporó la opción de implementar el procedimiento administrativo por medios electrónicos, se amplió los procedimientos de aprobación automática, se instauró procedimientos administrativos estandarizados obligatorios, se impuso a las entidades la obligación de permitir a otras el acceso gratuito a sus bases de datos y registros, se precisó la información que las entidades están prohibidas de solicitar a los administrados por ser redundante, etcétera. ${ }^{21}$

En ese sentido, se ha señalado que:

"La LPAG modificada por el Decreto Legislativo 1272, y la Ley de Eliminación de Barreras Burocráticas han recogido las recomendaciones de la OCDE en temas de simplificación administrativa. (...) No tenemos menor duda de que la normativa expuesta es perfectible; sin embargo, se ha avanzado en nuestro ordenamiento del Derecho Administrativo a fin de ser un país propio de la OCDE".22

También al finalizar el 2016 se emitió el Decreto Legislativo 1310, dentro del cual se introdujo, entre otras medidas, el denominado Análisis de Calidad Regulatoria. Este programa será analizado en la sección IV, bastando señalar aquí que recién empezó a rendir frutos entre 2018 y 2019.

Por ello, en la actualización de su estudio de diagnóstico del marco regulatorio peruano, emitida el año 2018, la OCDE continuaba identificando la falta de supervisión eficaz sobre la estrategia de simplificación administrativa:
"Aunque existe una estrategia de simplificación administrativa, no hay una supervisión eficaz de su aplicación. Estos esfuerzos se ven socavados aún más porque el gobierno peruano carece de un punto de referencia para medir las cargas administrativas que emanan de los trámites y obligaciones de AD información para empresas y ciudadanos, lo que puede dificultar la focalización de recursos y la comunicación de resultados. Además, las estrategias para digitalizar los trámites y servicios de gobierno electrónico aún son incipientes y están en sus etapas preliminares de desarrollo"23_-subrayado añadido-.

Así, la agenda en materia de simplificación aún se mostraba incompleta al 2018, al carecer de una metodología para sopesar las exigencias impuestas a la ciudadanía respecto de sus ventajas, y que a la larga permita no solo evaluar comparativamente los logros obtenidos, es decir el antes y el después, sino también programar los recursos necesarios y las metas a cumplirse.

\section{2. ¿Programas de AIR en Perú?}

En Perú no existe un sistema de AIR integral e institucionalizado, sino solamente algunos ámbitos de acción del estado que tienen sus características. A continuación, se explican los alcances y limitaciones de la evaluación de impacto regulatorio que existe en nuestro país.

\subsection{Análisis Costo-Beneficio para proyectos de ley y regulaciones de inferior jerarquía.}

El primer ámbito en que se identifica un rastro de evaluación de impacto de las normas se encuentra en las propuestas de ley. El año 1993 se

21. Milagros Maraví, "Mecanismos de Simplificación Administrativa la Luz de las Recientes Modificaciones a la Ley del Procedimiento Administrativo General, Ley 27444, y la reciente Ley de Prevención y Eliminación de Barreras Burocráticas, Decreto Legislativo 125", lus et Veritas 54 (2017).

22. Ibíd, 98-99.

23. Organización para la Cooperación y Desarrollo Económicos (2018). Política Regulatoria en el Perú. Uniendo el Marco para la Calidad Regulatoria: (2018), 24. 
incorporó, por primera vez en el Reglamento del Congreso, que las propuestas de ley podían incluir un Análisis Costo-Beneficio - ACB, a solicitud del presidente del Congreso o de una Comisión del Congreso. Dos años después, en el Reglamento del Congreso de 1995, se estableció como requisito que las propuestas de ley deben contener el ACB de la futura norma; y finalmente a través de una modificación del año 1998 se agregó que el ACB debía incluir el impacto en el medio ambiente ${ }^{24}$, quedando el siguiente texto en el Reglamento del Congreso que sigue vigente hasta la actualidad:

\section{"Artículo 75. Las proposiciones de ley deben contener una exposición de motivos donde se expresen sus fundamentos, el efecto de la vi- gencia de la norma que se propone sobre la le- gislación nacional, el análisis costo-beneficio de la futura norma legal incluido, cuando co- rresponda, un comentario sobre su incidencia ambiental. De ser el caso, la fórmula legal res- pectiva que estará dividida en títulos, capítu- los, secciones y artículos. Estos requisitos sólo pueden ser dispensados por motivos excepcio- nales. (...)".- - subrayado agregado- ${ }^{25}$}

Entre los años 1998 y 2005 se elaboraron diver- sos documentos para facilitar que se cumpliera con ese requisito, en los cuales se explicaban los requerimientos y etapas de la metodología de ACB completa - que incluye la cuantificación monetaria de costos y beneficios y su comparación-, pero contemplando también la posibilidad de elaborar versiones menos complejas y exhaustivas. La visión de estos documentos fue siempre ofrecer formas simplificadas de realizar el análisis, reduciendo paulatinamente los pasos a seguir a lo mínimo indispensable para tener una evaluación aceptable, y siempre con el objetivo de que los legisladores estuvieran suficientemente informados sobre los impactos de las propuestas legislativas. ${ }^{26}$

Sin embargo, como se sabe, el resultado del $A C B$ de los proyectos de ley en promedio es decepcionante hasta hoy, pues en la mayoría de los casos solo es una formalidad sin sustancia. Aun cuando el $A C B$ no tiene porqué ser un ejercicio extenso y plagado de cálculos y cifras, es razonable asumir que debería estar contenido en algunas páginas de evaluación consistente y bien sustentada. No obstante, las evaluaciones cuantitativas que se han ido reportado de tiempo en tiempo al respecto son esclarecedoras.

24. Según Hernández, el artículo 38 del Reglamento del Congreso Constituyente Democrático de 1993 señalaba lo siguiente: "El estudio de los proyectos de ley por el Comité de Asesoramiento, a solicitud del Presidente del Congreso o de cada Comisión, incluye un análisis costo-beneficio de la norma y de su viabilidad técnica y económica, así como un informe jurídico (...)". Sin perjuicio de ello, el artículo 75 del Reglamento del Congreso del año 1995 contempló ya como requisito de los proyectos de ley incluir en análisis costo beneficio: "Las proposiciones de ley deben contener una exposición de motivos donde se expresen sus fundamentos, el efecto de la vigencia de la norma que se propone sobre la legislación nacional, el análisis de costo-beneficio de la futura norma legal (...)". Roberto Hernández,"Análisis Costo-Beneficio en los Proyectos de Ley: Problema Estructural", Cuadernos Parlamentarios N ${ }^{\circ} 10$ (segundo trimestre 2014): 59-60.

25. Ver: http://www.congreso.gob.pe/Docs/biblioteca/files/reglamento/reglamento2020web.pdf, acceso el 20 de diciembre de 2021. Además, mediante el Decreto Supremo № 008-2006-JUS, Reglamento de la Ley 26889, Ley Marco para la Producción y Sistematización Legislativa, se estableció que todas las entidades públicas con capacidad para plantear proyectos de ley también están obligadas a incluir un ACB en la propuesta.

26. Estos fueron los sucesivos documentos que se trabajaron en esa época: (i) Gabriel Ortiz de Zevallos y Gustavo Guerra García, Introducción al Análisis Costo Beneficio de las Normas (Lima: Perú Económico, 1999); (ii) Comisión Andina de Juristas, capítulo VI, "Previsibilidad de la Ley y Análisis Costo Beneficio" en Manual Parlamentario (Lima: Comisión Andina de Juristas, 2002); (iii) Javier Tantaleán, Propuesta de Manual ACB Análisis Costo-Beneficio de los Proyectos de Ley (Lima, 2004); (iv) Servicio Parlamentario del Congreso de la República, Guía de orientación N 06-2005-DCD-DGP/CR Guía de Orientación del Análisis Costo-Beneficio Legislativo (Lima: Congreso de la República, 2005); y (v) Félix Arias-Schreiber, Antonio Peña y Luis Valdivieso, La Evaluación de las Leyes en el Perú: El Análisis Costo-Beneficio en el Congreso de la República (Lima: Fondo Editorial PUCP, 2019), 112-151. 
Así, por ejemplo, en 2003 se reportaba que, de una muestra de 65 proyectos de ley, el $87 \%$ tenía sección de $A C B$, pero estaba desarrollada en promedio en tan solo 12 líneas, mientras que solo $16 \%$ contenía alguna cifra numérica. En otra muestra de 347 proyectos de ley, el 99\% contenía una sección de ACB, pero en el $87 \%$ se desarrollaba entre 1 y 15 líneas. Para 2008 se reportaba que, de una muestra de 229 proyectos de ley, en el $72 \%$ la sección de ACB se concentraba en señalar que la propuesta no generaba gasto al erario nacional y solo algunos mencionaban que además de costos la propuesta generaba beneficios. En una evaluación realizada en 2011 respecto de una muestra de 387 proyectos de ley presentados desde agosto de 2006 hasta enero de 2011, se identificó que el $96 \%$ tenía una sección de $A C B$, de los cuales en el $81 \%$ el análisis se desarrollaba entre 1 y 14 líneas, mientras que el $61 \%$ señalaba que la propuesta que no irrogaba gasto público. ${ }^{27}$

Luego, en una evaluación selectiva realizada en 2013 por la Asociación Civil Transparencia sobre 81 proyectos presentados entre 2011 y 2013 se señalaba:

"(...) tres quintas partes de las propuestas de ley presentadas consideran que sus efectos no generan gastos; sin embargo, las consecuencias de dichas propuestas están relacionadas directamente con la mejora o desmejora de alguien en la sociedad, y ello tiene un costo que alguien necesariamente ha asumido $y$ que no se ha cuantificado".28

Además, si bien se ha identificado cierta evidencia estadística de que los proyectos sobre materia económico-financiera suelen tener un índice de calidad superior de $A C B$, de ello no puede inferirse que la evaluación sea adecua$\mathrm{da}$, sino solo que "tendencialmente la calidad del $A C B$ de los proyectos de ley aumenta cuando su contenido es económico". ${ }^{29}$

En términos más globales, el balance general del $A C B$ de los proyectos de ley es bastante ne-ADin gativo pues

"(...) cualquiera haya sido el indicador utilizado en los estudios, desde inicios de nuestro siglo se han obtenido siempre resultados bastante desalentadores. En ningún caso se ha superado la valla del $15 \%$ de proyectos de ley que, habiendo sido estudiados, presenten apenas adecuadamente desarrollados los aspectos sustantivos de la metodología del ACB." — subrayado añadido-_ ${ }^{30}$

Corresponde agregar que en el 2006 se dictó la Ley 26889, Ley Marco para la Producción y Sistematización Legislativa. Si bien esta norma no contiene reglas sobre AIR, su reglamento, aprobado mediante Decreto Supremo № 008-2006JUS, sí lo hace. En particular, señala que las Entidades de la Administración Pública que emitan Decretos Supremos que versen sobre materias económicas y financieras deben incluir un ACB. La norma señala que el $A C B$ permite cuantificar los costos y beneficios de las propuestas normativas o al menos apreciar analíticamente beneficios y costos no cuantificables. Además, establece que la necesidad de la norma propuesta debe justificarse considerando la naturaleza de los problemas, los costos y beneficios probables y los posibles mecanismos alternativos para solucionarlos. Para el caso de propuestas normativas reglamentarias se sustentarán los alcances, las implicancias y sus consecuencias, identificando a los potenciales beneficiarios y afectados en forma clara y sencilla.

27. Hernandez, "Análisis Costo-Beneficio en los Proyectos de Ley: Problema Estructural", 75-77.

28. Arias-Schreiber, et al, La Evaluación de las Leyes en el Perú... 181.

29. Ibíd, 251.

30. Ibíd,191. 
El mismo año 2006, el Ministerio de Economía y Finanzas - MEF, dictó la Resolución Ministerial № 639-2006-EF/67, mediante la cual aprobó el Manual para el Análisis Económico y Legal de la Producción Normativa en el MEF. Esta norma contempla varios principios y reglas típicas del AIR, como por ejemplo, el principio de efectividad, que exige que la norma tenga definido su objetivo y los mecanismos para alcanzarlos, incluyendo sus impactos económicos; el principio de proporcionalidad, que implica hacer un $A C B$, que permite evaluar si los costos a la sociedad de la intervención reguladora no son mayores que el problema que se busca solucionar; y el principio de transparencia, que lleva a que los proyectos normativos sean publicados para recibir comentarios. Asimismo, a través del resguardo de la calidad de las normas, se plantea que las autoridades revisen continuamente que las normas a su cargo sigan siendo eficientes $y$ efectivas, para definir su continuidad.

Sin perjuicio de que las normas antes señaladas existen y entendemos que se aplican, la implementación de las mismas para la evaluar la intervención reguladora de rango infra legal es poco conocida en cuanto a sus resultados. No se cuenta con un repositorio completo de los ACB que según la misma deben sustentar las propuestas de decreto supremo en las materias antes señaladas; es decir, no existe un sistema transparente y orgánico que permita comprobar que se ha cumplido con ese requisito, ni tampoco para revisar sistemáticamente la calidad del análisis realizado en cada caso.

Tan es así que en el estudio de diagnóstico de la política regulatoria del Perú que se elaboró en 2016, la OCDE identificó que a través de la Comisión de Coordinación Viceministerial - CCV, encabezada por el MEF, el Ministerio de Justicia -MINJUS, y la $\mathrm{PCM}^{31}$, se había establecido un sistema de evaluación de la calidad, pero solo de proyectos de regulación multisectorial y sin contemplar varios aspectos relevantes de un sistema de AIR. En ese sentido, la OCDE concluyó que:

"El proceso de creación regulatoria en Perú no cuenta con una política regulatoria integral: no se ha implementado un proceso sistemático de evaluación ex ante de la regulación; en la práctica la profundidad del análisis costo-beneficio difiere según el tipo de regulación; no se consideran alternativas y enfoques para combatir la problemática; no existen lineamientos homogéneos sobre la consulta pública, el involucramiento de actores interesados y el tratamiento de los comentarios recibidos; no existe una programación sobre la emisión y modificación de regulaciones; y la evaluación sobre la calidad legal de las propuestas regulatorias es poco profunda y no es homogénea." - subrayado añadido- ${ }^{32}$

Esta evaluación no cambió en el 2018, cuando la OCDE hizo la actualización del referido estudio de diagnóstico, pues en este documento concluyó que:

"Aunque Perú cuenta con algunos de los elementos básicos, carece de un sistema exhaustivo para la evaluación ex ante de los anteproyectos de normativas y los reglamentos que están sujetos a modificaciones, para valorar si brindan un beneficio positivo neto a la sociedad y si son congruentes con otras políticas gubernamentales. ${ }^{1 / 33}$ —subrayado añadido-

Además, si bien la OCDE reconoció que la CCV era un mecanismo para evaluar la calidad de los proyectos, señaló que tiene un poder de veto

31. La OCDE señala que el MEF se concentra en el ACB; el MINJUS en el análisis de constitucionalidad, legalidad y calidad legal; y la PCM verifica que sea consistente con los lineamientos de simplificación administrativa.

32. OCDE, Política Regulatoria en el Perú. (2016), 114-15.

33. OCDE, Política Regulatoria en el Perú. (2018), 21. 
de facto para bloquear su aprobación, ya que los 35 viceministerios que la conforman tienen potestad para señalar objeciones de fondo o calidad sobre dichos proyectos y se requiere levantarlas para su aprobación. En ese sentido, la OCDE señaló que "(...) existe el riesgo de que la CCV pueda crear cuellos de botella en el proceso normativo, o que tal vez aparezcan estrategias de negociación con ventajas e inconvenientes negativos entre los viceministerios ${ }^{134}$. —subrayado añadido-

\subsection{Principios de AIR en la regulación de ser- vicios públicos. ${ }^{35}$}

Los organismos reguladores de servicios públicos peruanos - OSINERGMIN, OSIPTEL, OSITRAN y SUNASS - tienen asignadas diversas facultades desde su creación relacionadas con sus funciones normativa y de fijación de precios o reguladora propiamente dicha, así como con sus actividades de supervisión, fiscalización y sanción del comportamiento de los agentes de sus respectivos mercados. ${ }^{36}$

Cada uno de los reguladores fueron dotados individualmente en cada uno de sus reglamentos generales desde el año 2001 con herramientas para llevar a cabo una evaluación del impacto de sus regulaciones y acciones de fiscalización y sanción. ${ }^{37}$ En particular, en cada reglamento se estableció un conjunto de principios rectores de su actuación que contienen enunciados varios elementos típicos de un sistema de AIR, siendo los más relevantes para estos efectos los principios de subsidiariedad, actuación basada en el análisis costo beneficio, eficiencia y efectividad, y análisis de decisiones funcionales. Solo a manera de ejemplo, se señalan a continuación los textos correspondientes a los referidos principios contenidos en algunos de los reglamentos del regulador indicado:

a) Principio de subsidiariedad del OSITRAN: ADMINISTRATIVO En el ejercicio de su función normativa y/o reguladora, la actuación del OSITRAN es subsidiaria y solo procede en aquellos supuestos en los que el mercado y los mecanismos de libre competencia no sean adecuados para el desarrollo de los mercados y la satisfacción de los intereses de los usuarios. En caso de duda sobre la necesidad de dictar disposiciones normativas y/o reguladoras, se optará por no dictarlas. Entre varias opciones similarmente efectivas, se optará por la que afecta menos la autonomía privada - artículo 10-.

b) Principio de análisis costo-beneficio del OSINERGMIN: Los beneficios y costos de las acciones emprendidas por el OSINERGMIN, en lo posible, serán evaluados antes de su realización y deberán ser adecuadamente sustentados en estudios y evaluaciones técnicas que acrediten su racionalidad y eficacia. Esta evaluación tomará en cuenta tanto las proyecciones de corto como de largo plazo, así como los costos y beneficios directos e indirectos monetarios o no monetarios. Serán considerados tanto los costos para el desarrollo de las acciones planteadas por el OSINERGMIN, así como los costos que la regulación impone a otras entidades del estado y del sector privado -artículo 7-.

34. Ibid, 22.

35. En esta sección seguimos en buena parte lo expuesto en un trabajo previo: Eduardo Quintana, “Análisis de Impacto Regulatorio en la Regulación Peruana de Servicios Públicos", Derecho \& Sociedad 36 (2011).

36. Ley 27332, Ley Marco de los Organismos Reguladores de la Inversión Privada en Servicios Públicos —artículo 3 y su Reglamento, aprobado por Decreto Supremo N 042-2005-PCM —artículo 2—.

37. Decreto Supremo N 008-2001-PCM, Reglamento General del OSIPTEL; Decreto Supremo N 017-2001-PCM, Reglamento General de la SUNASS; Decreto Supremo N 054-2001-PCM, Reglamento General del OSINERGMIN; Decreto Supremo Nº44-2006-PCM, Reglamento General del OSITRAN. 
c) Principio de eficiencia y efectividad del OSIPTEL: La actuación de OSIPTEL se guiará por la búsqueda de eficiencia en la asignación de recursos y el logro de los objetivos al menor costo posible para la sociedad en su conjunto - artículo 14-.

d) Principio de análisis de decisiones funcionales del OSIPTEL: El análisis de las decisiones funcionales del OSIPTEL tendrá en cuenta sus efectos en los aspectos de fijación de tarifas, calidad, incentivos para la innovación, condiciones contractuales y todo otro aspecto relevante para el desarrollo de los mercados y la satisfacción de los intereses de los usuarios. En tal sentido, deberá evaluarse el impacto que cada uno de estos aspectos tiene en las demás materias involucradas - artículo 13-.

Como se observa, el principio de subsidiariedad no solo exige evaluar distintas opciones regulatorias, para optar por la que menos restrinja la autonomía privada, sino además incluye considerar la opción de no regular. Asimismo, los principios de análisis costo-beneficio y de eficiencia y efectividad, suponen la identificación de los costos y beneficios de las opciones regulatorias evaluadas, así como su comparación. El principio de decisiones funcionales no determina un parámetro para la evaluación, pero señala los principales ámbitos en que la misma debe realizarse.

Si bien los reglamentos de los reguladores no definen si existe prioridad en la aplicación de los métodos de evaluación de impacto, no cabe duda de que se trata de principios que deben ser cumplidos de manera obligatoria por los reguladores al ejercer sus funciones. ${ }^{38}$

Sin embargo, los reguladores no establecieron un sistema de AIR integral en base al mandato de los referidos principios. Solo recurrieron a ellos esporádicamente según consideraron apropiado o eventualmente necesario. Paulatinamente, los reguladores fueron realizando mayores esfuerzos para sofisticar su evaluación de impacto y además para generar mecanismos de consulta más sistemáticos, pero sin estructurar un sistema de AIR completo que incluyera someter a consulta el AIR.

Por ello, en su estudio de diagnóstico del 2016 la OCDE señaló que "a pesar de que llevan a cabo estudios de costo-beneficio más elaborados en comparación con el gobierno central, estos podrán ser mejorados a través de guías y manuales". En tal virtud, planteó como recomendación específica para los reguladores introducir un sistema de AIR distinto al del gobierno general:

"El sistema debe contar con un mecanismo para que distinga las regulaciones de mayor impacto para que se les aplique un análisis más profundo. Adicionalmente, se deben emitir manuales y guías de proceso de RIA y llevar a cabo talleres de capacitación para los oficiales de gobierno; así como disposiciones para evaluar la calidad de las RIA. Finalmente, como parte del proceso de consulta de los proyectos regulatorios, las RIA deben ser publicadas". 39

Como consecuencia de esta recomendación, los reguladores tomaron en serio la necesidad de institucionalizar sus sistemas de AIR y han aprobado lineamientos detallados sobre la materia.

Así, por ejemplo, mediante Acuerdo del Consejo Directivo del OSINERGMIN № 01-13-2016, se aprobó la Guía para la realización del RIA de este

38. Al respecto, el Reglamento General de cada regulador contiene una sección especial sobre principios regulatorios y el primer artículo de tal sección se titula así: "Importancia de los Principios". Este artículo señala sin excepción que "Los principios contenidos en el presente Título establecen las bases y lineamientos de la acción de [regulador] en el desarrollo y ejercicio de sus funciones. En tal sentido, toda decisión y acción que adopte cualquiera de los órganos funcionales de [regulador correspondiente] deberá sustentarse y quedar sujeta a los mismos". 
regulador. Posteriormente, a través de la Resolución No 130-2020-OS/CD, se aprobó la actualización de la referida Guía de AIR, para darle mayor importancia al proceso de consulta pública, y se precisan aspectos para la mejor identificación del problema, los objetivos de la intervención reguladora, entre otros. Por su parte, mediante Resolución No 069-2018-CD/OSIPTEL, se aprobó no solo los Lineamientos de Calidad Regulatoria del OSIPTEL, sino también su Manual de la Declaración de Calidad Regulatoria y el Manual de Técnica Normativa de la entidad.

De esta manera, los reguladores de servicios públicos vienen siendo el estamento del estado peruano que más claramente se ha comprometido con la tarea de establecer un sistema integral de AIR y están buscando implementarlo de manera sostenida.

Sin perjuicio de ello, debe mencionarse que, en la actualización del estudio de diagnóstico del 2018, la OCDE señaló que:

"(...) el análisis y la utilización de criterios oficiales para preparar la evaluación podrían mejorarse. En general, los órganos reguladores económicos no acatan directrices cuando preparan los análisis de costo/beneficio". Por ello recomendó que: "Deben tomarse medidas para dirigir los recursos y analizar más a fondo las regulaciones con las repercusiones más importantes. (...) Los órganos reguladores deberán establecer sus propias disposiciones para asegurar y evaluar la calidad de sus propias evaluaciones de impacto regulatorio $(\ldots)^{\prime \prime} .40$

2.3 Evaluación ex post del impacto de las regulaciones sobre el acceso o permanencia en el mercado.

Para cerrar la descripción de los esfuerzos desplegados en el Perú para realizar la evaluación del impacto de las regulaciones, se debe men- cionar el caso del INDECOPI, que administra un sistema de evaluación ex post del impacto de la regulación a través de la Comisión de Eliminación de Barreras Burocráticas - antes Comisión de Acceso al Mercado-y del Tribunal de la entidad.

Antes ya se ha mencionado que esta Comisión fue creada en 1992 con el mandato de revisar e inaplicar actos y disposiciones de las entidades de la Administración Pública, incluso del ámbito municipal o regional, que impongan barreras burocráticas que impidan u obstaculicen ilegal o irracionalmente el acceso o permanencia de los agentes económicos en el mercado. Al ejercer sus funciones respecto de las barreras burocráticas irracionales, el INDECOPI estableció un conjunto de reglas de evaluación del impacto de la regulación sobre la entrada o permanencia de las empresas en el mercado.

En efecto, a través de la aprobación de un precedente de observancia obligatoria, el INDECOPI estableció en 1997 una metodología para evaluar si las regulaciones calificaban como barreras burocráticas irracionales ${ }^{41}$, considerando los siguientes tres niveles de análisis: (i) si la medida cuestionada tiene sustento de interés público, para lo cual la entidad de la Administración Pública debe demostrar la existencia del interés público tutelable y que la medida adoptada es idónea para solucionar el problema que afecta dicho interés público; (ii) si la medida es proporcional a sus fines, para lo que debe acreditar que la implementación de la medida objetada genera mayores beneficios que los costos que impone; y (iii) que la medida es la opción menos gravosa para lograrlos, lo que implica que se debe demostrar que la opción adoptada es la alternativa que menos afecta la libre iniciativa privada para tutelar el interés público comprometido.

Esta metodología se aplicó por varios años, aunque solo residualmente, puesto que el IN-

40. OCDE, Política Regulatoria en el Perú. (2018), 33 y 34.

41. Resolución No 182-97-TDC. 
DECOPI estableció que no evaluaría la racionalidad de la medida en cuestión si primero se concluía que era una barrera burocrática ilegal, lo que suele ocurrir en la mayoría de los casos que ha conocido la entidad. Adicionalmente, los casos declarados fundados por irracionalidad tampoco son muchos, porque el estándar de prueba requerido por el INDECOPI sobre indicios de falta de razonabilidad suele ser elevado, e incluso requiere que el denunciante demuestre que había otras medidas alternativas menos gravosas. ${ }^{42}$

En el año 2016 la metodología de evaluación ex post de la racionalidad de las regulaciones del INDECOPI se elevó al rango de ley a través de la aprobación del Decreto Legislativo 1256, Ley de Prevención y Eliminación de Barreras Burocráticas. Esta norma establece que la razonabilidad de una barrera burocrática debe verificarse definiendo: (i) si la medida no es arbitraria, lo que implica acreditar la existencia del interés público que la sustentó y del problema que se pretende solucionar con la medida, así como que la medida es idónea para lograr la solución del problema; (ii) si la medida es proporcional a sus fines, lo que implica una evaluación de los beneficios y/o el impacto positivo que generaría y de los costos y/o el impacto negativo de la misma, y verificar si genera mayores beneficios que costos, así como que otras medidas alternativas no resultarían menos costosas o no serían igualmente efectivas, lo que incluye la posibilidad de no emitir una nueva regulación.

Dados los alcances de la referida metodología, se observa que se trata de un sistema de evaluación ex post del impacto de las regulaciones, pero tiene un alcance acotado solamente en lo que respecta al acceso o permanencia de los agentes económicos en el mercado. Es decir, se trata de una evaluación de impacto ex post limitada a la razonabilidad de los costos de cumplimiento que exigen las regulaciones a los administrados. En ese sentido, la OCDE concluyó lo siguiente en su estudio de diagnóstico del año 2018:

"(...) no se encontró prueba alguna de que en el país se hagan evaluaciones ex post de las leyes o normativas vigentes. La única excepción identificada fueron las investigaciones que realiza la Comisión de Eliminación de Barreras Burocráticas, pero éstas se centran sólo en evaluar la validez legal o 'justificación razonable' de los trámites existentes o de las peticiones de requisitos de datos como parte de los trámites, más que en evaluar textos legislativos completos, instrumentos normativos o regulaciones que afectan sectores económicos específicos $^{1 / 43}$ - subrayado añadido-.

Habiendo pasado revista a todas las normas, lineamientos y metodologías que pueden considerarse asociadas al AIR, se concluye que en el Perú no existe un sistema AIR integral e institucionalizado, sino tan solo manifestaciones de evaluación de impacto dispersas y con distinto nivel de profundidad y/o alcance.

\section{ANÁLISIS DE CALIDAD REGULATORIA - ACR - EN PERÚ}

En línea con lo antes expresado, en su estudio de diagnóstico del 2016 la OCDE señaló que no bastaba que el Perú hubiera implementado un amplio programa de simplificación administrativa y que existan ámbitos en que sea obligatorio hacer un ACB de las normas, sino que era necesario (i) adoptar una política de calidad regulatoria, incluyendo (ii) un sistema integral de AIR y (iii) un régimen de medición y reducción de las cargas administrativas, (iv) bajo la batu-

42. Sofía Ugás y Giuliana Paredes, “El análisis de razonabilidad a través de los pronunciamientos del INDECOPI: cómo evitar medidas impuestas utilizando el 'De tin marin de do pingüe'", Revista de la Competencia y de la Propiedad Intelectual 10 (19): 91.

43. OCDE, Política Regulatoria en el Perú. (2018) 26. 
ta de un órgano rector que tenga el mandato específico de implementar la referida política. ${ }^{44}$

Es decir, al 2016 no solo se tenía un diagnóstico de las falencias de la reforma regulatoria peruana, sino también la identificación específica de las medidas que podían adoptarse para completarla.

Como ya se ha adelantado, a fines del 2016 se emitió, entre otras normas, el Decreto Legislativo 1310 para atender las recomendaciones de la OCDE. En particular, a través del artículo 2 del Decreto Legislativo 1310 —en adelante DL 1310 - se estableció el ACR de procedimientos administrativos, y su Reglamento se aprobó unos meses después mediante Decreto Supremo No 075-2017-PCM.

Con estas normas se inició una nueva etapa en la agenda de reforma regulatoria peruana, creándose un sistema de ACR estructurado, con metas de revisión de impacto específicas, gatilladores para que las normas o proyectos de normas sin ACR no tuvieran efectos, y bajo la rectoría y supervisión de una nueva instancia dentro del aparato estatal encargada de validar los ACR específicos llevados a cabo por las diversas entidades públicas.

Sin perjuicio de ello, corresponde mencionar que en el camino hubo un cambio de giro importante, debido a una aparente confusión sobre la naturaleza y objetivo del sistema de ACR aprobado, que lo asemejaría al AIR, cuando lo que se buscaba era solamente un mecanismo de simplificación administrativa.

En efecto, en el año 2018 se aprobó el Decreto
Legislativo 1448 —en adelante DL 1448 - para modificar el artículo 2 antes señalado. El año siguiente se aprobaría el nuevo Reglamento del sistema de ACR a través del Decreto Supremo No 075-2019-PCM. El principal motivo de esta modificación fue precisar que el ACR tiene por objetivo crear un sistema para determinar y re-ADMINISTRATIVO ducir las cargas regulatorias generadas por los procedimientos administrativos, y no crear un sistema de AIR para evaluar los impactos positivos y negativos de las regulaciones sustantivas. En la exposición de motivos del DL 1448 se explicó así el "problema":

"(...) el objeto del Análisis de Calidad Regulatoria es el procedimiento administrativo. No obstante, la redacción del artículo 2 del Decreto Legislativo No 1310 resulta confusa al hacer referencia en sus diversos párrafos a la "disposición normativa" como objeto de análisis. Como consecuencia de ello, diversos actores públicos y privados consideraron que la implementación del Decreto Legislativo $N^{\circ}$ 1310 implicaba el análisis de la norma sustantiva con el fin de determinar sus posibles impactos (positivos y negativos), el cual es parte del Análisis de Impacto Regulatorio (RIA, por sus siglas en inglés), y no de una metodología de simplificación administrativa como el $\underline{A C R}$. La falta de claridad respecto del objeto y finalidad del $A C R$ es reforzada cuando en el párrafo 2.2 se establece entre los principios del ACR el de costo-beneficio. El costo-beneficio es un método para analizar el impacto de la regulación propio de la metodología RIA. Debe señalarse que mientras el RIA es el principal instrumento para analizar los impactos de las propuestas regulatorias, la simplificación de procedimientos se realiza mediante

44. En particular la OCDE concluyó que: "Perú cuenta con muchos elementos concretos de política regulatoria en vigor. Por ejemplo, las agencias y los ministerios tienen la obligación de realizar un análisis costo-beneficio para conjuntos específicos de borradores de regulación, y de poner a disposición del público estos borradores. Un amplio programa de simplificación administrativa abarca los niveles de gobierno central y sub-nacional. Sin embargo, Perú aún enfrenta muchos desafíos en la creación de un marco regulatorio general de alta calidad. Para enfrentar estos desafíos, el estudio recomienda varios pasos, incluyendo el establecer una política de calidad regulatoria para reunir e impulsar los elementos ya existentes, la creación de un órgano supervisor, establecer un sistema de análisis de impacto regulatorio, y la medición y reducción las cargas administrativas de los trámites" - el subrayado es nuestro-. OCDE, Política Regulatoria en el Perú. (2016), 3. 
métodos para identificar y reducir los costos (cargas administrativas) que originan su tra$\underline{\text { mitación }}^{\prime \prime 45}$ —subrayado añadido-.

Luego de estas modificaciones y del enrutamiento del sistema de ACR peruano, se tiene que las características más relevantes del mismo son las siguientes:

a) Obligación de realizar el ACR: se ordenó a las entidades del Poder Ejecutivo realizar un ACR de todas las normas de rango inferior a la ley que establezcan procedimientos administrativos, con el objetivo de identificar, reducir o eliminar los que sean innecesarios, injustificados, desproporcionados, redundantes o no se adecúen a la LPAG.

b) Alcance del ACR concentrado en las cargas administrativas: Se estableció que el ACR es un proceso integral y continuo de análisis de disposiciones de carácter general que creen procedimientos administrativos, cuyo objetivo es la "determinación y reducción de las cargas administrativas". Las cargas administrativas se definen como "los costos en los que incurren los administrados como consecuencia del cumplimiento de las obligaciones de información impuestas por la regulación en el trámite de un procedimiento administrativo". Y la obligación de información se califica como "la exigencia establecida en una disposición normativa de carácter general que tiene el administrado para presentar documentos, declaraciones, informaciones, actuaciones, diligencias y demás requisitos señalados en la tramitación de un procedimiento administrativo" -numerales 3.2, 3.3. y 3.7 del Reglamento, respectivamente - subrayado añadido-.

c) Criterios de evaluación: se definió los siguientes principios para guiar la validación o descarte de los procedimientos administrativos: i. Legalidad: los procedimientos administrativos se crean con respeto al marco legal, dentro de las facultades atribuidas y para lograr los fines para los que fueron conferidas.

ii. Necesidad: el procedimiento administrativo contribuye a resolver un problema relevante, considerando si existen o no mejores alternativas para resolverlo distintas al procedimiento administrativo.

iii. Efectividad: cada obligación de información es relevante por contribuir efectivamente a lograr el objetivo del procedimiento administrativo, eliminándose toda complejidad innecesaria.

iv. Proporcionalidad: analizar la debida proporción entre el objetivo del procedimiento administrativo y las obligaciones de información exigidas a los administrados mediante la determinación y reducción de las cargas administrativas.

Estos principios funcionan como filtro, pues los procedimientos que incumplen los principios de legalidad y/o de necesidad se eliminan o no entran en vigor, mientras que el incumplimiento de los principios de efectividad y/o de proporcionalidad ocasiona la eliminación y/o simplificación de requisitos para la reducción de las cargas administrativas.

d) Instancia rectora del sistema de ACR: se creó la Comisión Multisectorial de Calidad Regulatoria presidida por la PCM y conformada por representantes del MEF y del MINJUS, para que revise y valide los reportes de ACR que realicen las distintas entidades.

45. La referida exposición de motivos puede ser leída en el siguiente enlace: https://leyes.congreso.gob.pe/Documentos/2016_2021/Decretos/Legislativos/2018/DL144820180918.pdf, acceso el 15 de enero de 2021. 
e) Programación de revisión de ACR y consecuencias de no realizarla: Se estableció los siguientes parámetros de vigencia de las normas que crean procedimientos administrativos, de modo que queden suje- tas al ACR en todas sus posibles variantes - proyectos de norma, normas vigentes, y modificaciones-, incluyéndose además su revisión periódica:

\begin{tabular}{l|l|l}
$\begin{array}{l}\text { Normas } \\
\text { sujetas a ACR }\end{array}$ & $\begin{array}{l}\text { Oportunidad para } \\
\text { realizar el ACR }\end{array}$ & $\begin{array}{l}\text { ACR no aprobado } \\
\text { o inexistente }\end{array}$ \\
\hline $\begin{array}{l}\text { Existentes a la entrada } \\
\text { en vigor del DL 1310 }\end{array}$ & Según cronograma de revisión & Derogadas automáticamente \\
\hline $\begin{array}{l}\text { Emitidas luego de la } \\
\text { vigencia del DL 1310 }\end{array}$ & Antes de su aprobación & No pueden entrar en vigor \\
\hline $\begin{array}{l}\text { Todas las normas vigentes } \\
\text { o su última revisión }\end{array}$ & Cada tres años de vigencia & Derogadas automáticamente \\
\hline $\begin{array}{l}\text { Modificaciones a } \\
\text { normas vigentes }\end{array}$ & Antes de su aprobación & No pueden entrar en vigor \\
\hline
\end{tabular}

En el Manual de ACR aprobado por la PCM se sintetizó la metodología de cuantificación de las cargas administrativas en dos pasos. Primero, se identifican las obligaciones de información derivadas de las normas que establecen los procedimientos y que abarcan los documentos, declaraciones, informaciones, actuaciones, diligencias y otros requisitos que debe cumplir el administrado en la tramitación de un procedimiento. Segundo, se estima las cargas administrativas, para lo que se suman los costos en tiempo invertido para tener cada uno de los requisitos exigidos multiplicado por una tarifa por unidad de tiempo, más los costos monetarios dedicados a completar cada requisito. ${ }^{46}$

Como se observa, esta metodología replica el Modelo Costo Estándar propugnado por la OCDE desde los años 1990. El uso de esta metodología hace sentido si se tiene en cuenta que una de las recomendaciones de la OCDE en 2016 fue que se requería medir y reducir las cargas de los trámites administrativos, para cuantificar objetivamente la reducción de sobrecostos y, en particular, para tener una línea de base para futuras comparaciones.

Considerando el cronograma de revisión establecido, desde fines del año 2018 se empezaron a reportar los resultados del sistema de ACR considerando los primeros sectores que se sometieron al proceso de revisión y validación de procedimientos administrativos, entre los que se encontraba la PCM — que incluye, entre otros, al INDECOPI y tres reguladores de servicios públicos— ${ }^{47}$. De las 319 fichas de ACR ingresadas a ese momento, se validó $74 \%$ de los procedimientos, mientras que $10 \%$ fueron eliminados por no cumplir los criterios de legalidad o necesidad, y $16 \%$ se declararon impro-

46. Secretaría de Gestión Pública de la Presidencia del Consejo de Ministros, Manual para la Aplicación del Análisis de Calidad Regulatoria aprobado mediante Resolución Ministerial № 196-2017-PCM, acceso el 17 de enero de 2021, https://sgp.pcm.gob.pe/wp-content/uploads/2017/09/Manual-Analisis-Calidad-Regulatoria.pdf

47. Secretaría Técnica de la Comisión de Calidad Regulatoria, Informe N001-2018-CCR-ST - Resultados sobre el Análisis de Calidad Regulatoria del Primer Grupo del ACR Stock. Sector: Comercio Exterior y Turismo, Ambiente y Presidencia del Consejo de Ministros (publicado el 5 de noviembre de 2018). Se ratificó 237 procedimientos que fueron validados en este reporte. 
cedentes. ${ }^{48}$ Estos reportes se fueron emitiendo periódicamente según los avances por sectores, con distintas distribuciones de resultados, hasta el último emitido a mediados del 2019, en que se reportó que de las 514 fichas de ACR ingresadas, se validó el $52 \%$ de los procedimientos, $22 \%$ fueron eliminados por no cumplir los criterios de legalidad o necesidad, y $26 \%$ fueron declarados improcedentes. ${ }^{49}$

El resultado final del proceso de revisión de ACR fue que 62 entidades del Poder Ejecutivo sometieron a evaluación sus procedimientos ${ }^{50}$, se analizaron 2432 fichas de ACR, ratificándose 1439 procedimientos $-59 \%$ - eliminándose $319-19 \%$ - y declarándose improcedentes $674-28 \%$ - El sector con más procedimientos ratificados fue Agricultura y Riesgo con 248 y el sector con más procedimientos eliminados fue Salud con 59. Según las cuantificaciones realizadas, se redujo las cargas administrativas en aproximadamente 286.3 millones de soles, debido a la eliminación de procedimientos y/o simplificación de requisitos. Pero el principal logro es que: "Las entidades del Poder Ejecutivo han establecido una línea de base de los costos que generan las cargas administrativas, lo que permitirá simplificar más los procedimientos administrativos en los siguientes ciclos de revisión" ${ }^{\prime 51}$

Como se ha explicado en la primera sección de este trabajo, un programa moderno de reforma regulatoria se sustenta en mecanismos institucionalizados de AIR, con procesos de consulta pública sistemática y asignación de un ente responsable de hacer funcionar el sistema. Aun cuando la simplificación administrativa es importante, se concentra en normas adjetivas, mientras que el AIR se enfoca en las normas sustantivas que afectan sectores económicos y definen la competencia, innovación y productividad de las actividades productivas y de servicios.

Tal como señaló la OCDE en el estudio más reciente que ha realizado el año 2019, la reforma regulatoria en Perú seguía estando incompleta:

"Un paso importante es la introducción del Análisis de Calidad Regulatorio que crea un proceso de evaluación ex ante de los procedimientos administrativos para redactar reglamentos. Su implementación significa el primer proceso sistematizado en el Gobierno del Perú para evaluar los impactos de nuevas reglas. Al enfocarse sólo en procedimientos administrativos el alcance del Análisis de Calidad Regulatoria no iguala el de un sistema de AIR, en el cual se evalúa la normativa de forma integral.

Destaca la reciente creación de un comité formado por la Presidencia del Consejo de Ministros, el Ministerio de Economía y Finanzas y el Ministerio de Justicia y Derechos Humanos a cargo de un programa piloto de

48. La calificación de improcedente significa que son casos excluidos de la aplicación del ACR debido, por ejemplo, a que son procedimientos creados por norma con rango de ley, que no crean nuevos procedimientos, que se refieren a procedimientos administrativos sancionadores, que involucran procedimientos de naturaleza tributaria o el ejercicio de facultades de fijación de tarifas de los reguladores, entre otros.

49. Secretaría Técnica de la Comisión de Calidad Regulatoria, Informe Nº06-2019-CCR-ST - Resultados sobre el Análisis de Calidad Regulatoria del Primer Grupo del ACR Stock. Entidades Comprendidas en los Sectores: Economía y Finanzas, Salud, Defensa e Interior (publicado el 24 de junio de 2019). Se ratificó 267 procedimientos que fueron validados en este reporte.

50. El universo de potenciales entidades a evaluar era de 90 , pero 23 señalaron que no tenían procedimientos administrativos sujetos al sistema de ACR y 5 estaban aún en proceso de adecuación.

51. Secretaría de Gestión Pública de la Presidencia del Consejo de Ministros, Perú: La Experiencia con el Análisis de Calidad Regulatoria - ACR (Lima: Secretaría de Gestión Pública, 2019), 5, acceso el 12 de enero de 2021, https://sgp.pcm.gob.pe/wp-content/uploads/2019/12/Per\%c3\%ba-La-experiencia-con-el-An\%c3\%a1lisis-de-Calidad-Regulatoria-ACR.pdf 
evaluación ex ante a través de un AIR simplificado. Sin embargo, el comité funciona sin tener un mandato legal aún, y no ha generado guías ni directrices para que los ministerios o dependencias del gobierno preparen el AIR. (...)

El proceso de emisión de normativa es una práctica no estandarizada, ya que no cuenta con un instrumento específico de política regulatoria que lo sustente.

En este proceso es notorio que no existe supervisión o rendición de cuentas formalizada sobre la forma en que se lleva a cabo la emisión de la regulación al menos desde un punto de vista integral.

(...)

La consulta pública del proyecto regulatorio sólo se usa de forma intermitente ${ }^{152}$ - subrayado añadido-.

Como se observa, aun habiendo dado un paso importante con el ACR, el mismo no se compara con un sistema de AIR integral, y los mecanismos de evaluación de impacto que existen en el Perú son incipientes y necesitan considerables mejoras.

\section{EL REGLAMENTO DE AIR: UN ESFUERZO FRÁGIL PARA LA REFORMA REGULATO- RIA INTEGRAL}

Sin perjuicio de lo anterior, corresponde señalar que a través del DL 1448 también se contempló, aunque de modo bastante genérico y en unas pocas líneas, la existencia de un proceso de mejora de la calidad regulatoria orientado a que el ejercicio de la función normativa del Estado promueva la eficiencia y eficacia, en un marco de transparencia y neutralidad. Igualmente, se expresó que la cultura de gestión gubernamental centrada en el ciudadano fomenta que la decisión de las autoridades de regular se base en evidencia, racionalidad, y evaluación de impactos para facilitar el bienestar social. Así, en el artículo 4 del DL 1448 se señala:

\section{"Artículo 4.- La mejora de la calidad regula- toria}

La mejora de la calidad regulatoria es Un ADMINISTRATIVO proceso ordenado, integral, coordinado, gradual y continuo orientado a promover la eficiencia, eficacia, transparencia y neutralidad en el ejercicio de la función normativa del Estado. Fomenta una cultura de gestión gubernamental centrada en el ciudadano, por la cual la Administración Pública decide usar la regulación como un instrumento para alcanzar un objetivo de política pública, adoptando la decisión de regular basado en evidencia, racionalidad, evaluación de sus posibles impactos y cargas administrativas con la finalidad de generar y facilitar el desarrollo integral y bienestar social" - subrayado añadido-.

Los términos de esta norma no contemplan ningún mandato directo e inmediato para implementar la mejora de la calidad regulatoria, sino más bien solo contienen enunciados sobre lo que puede esperarse de ella. Asimismo, enuncian el tipo de cultura que se fomenta con la mejora regulatoria, pero sin establecer ninguna exigencia específica ni tampoco consecuencias por no actuar en consonancia con dicho proceso. ${ }^{53}$

En la misma línea de lo anterior, en el artículo 5 del DL 1448 se lista sin jerarquía, sistematización, o prioridad, lo que se considera instrumentos de mejora de la calidad regulatoria:

"Artículo 5.- Instrumentos para la mejora de la calidad regulatoria

Son instrumentos para la mejora de la cali-

52. Organización para la Cooperación y Desarrollo Económicos, Implementación del Análisis de Impacto Regulatorio en el Gobierno Central del Perú: Estudios de caso 2014-16. (París: OECD Publishing, 2019), p. 11-12.

53. En esta parte reproducimos algunos argumentos ya expresados en Eduardo Quintana, “Reglamentación del Análisis de Impacto Regulatorio en Perú: ¿Mucho ruido y pocas nueces?", Boletín BFE+ (2021), https://bfe.pe/boletin/2021/04/26/reglamentacion-del-analisis-de-impacto-regulatorio-en-peru-mucho-ruido-y-pocas-nueces/ 
dad regulatoria, de manera enunciativa y no limitativa, los siguientes:

a) La simplificación administrativa.

b) El Análisis de Calidad Regulatoria de procedimientos administrativos.

c) El análisis de impacto regulatorio ex ante yexpost.

d) La consulta a través de sus diversas modalidades.

e) El costeo de la regulación y de trámites.

f) Las revisiones y derogaciones del ordenamiento jurídico.

g) Otros que se establezcan por decreto supremo." — subrayado añadido-

Como se observa, este artículo no solo carece de explicaciones sobre los instrumentos listados, sino que se identifica que hay duplicidad en ellos. De un lado, el costeo de los trámites es parte del ACR, como también lo son las revisiones y derogaciones de procedimientos administrativos, y el ACR es solo una especie del género simplificación administrativa. De otro lado, el costeo de la regulación y la consulta pública son elementos inherentes a cualquier mecanismo de AIR, y la revisión y derogación de regulaciones son consecuencias esperables del AIR ex post. Esta redundancia no parece tener explicación alguna.

Se dice que las comparaciones son odiosas, pero la diferencia es notoria con respecto al contenido de los artículos del DL 1310 y DL 1448 sobre el ACR. En efecto, en estas normas se ha establecido con precisión y detalle lo siguiente sobre el ACR: (i) un mandato legal explícito y de aplicación cuasi inmediata, (ii) las obligaciones específicas a ser cumplidas en etapas pre determinadas; (iii) las consecuencias — drásticaspor incumplimiento, manifestadas en la vigencia o no de los procedimientos administrativos; (iv) los principios de fondo a ser evaluados a través de este mecanismo; (v) la autoridad encargada de administrar el mecanismo; entre otros. Nada de esto se prevé para el AIR en el DL 1448.

Pero eso no es todo. En vez de incluir al menos un desarrollo mínimo respecto de un instrumento tan importante para la agenda de mejora regulatoria, solo se contempló que el instrumento referido al AIR se aprobaría mediante Decreto Supremo que sería dictado en un plazo máximo de 180 días calendario..$^{54}$ Como el DL 1448 fue publicado en setiembre de 2018, el Decreto Supremo mencionado debía emitirse hasta marzo de 2019.

En la práctica, recién el 3 de abril de 2021 se publicó el Decreto Supremo № 063-2021-PCM, Reglamento que desarrolla el Marco Institucional que rige el Proceso de Mejora de la Calidad Regulatoria y establece los Lineamientos Generales para la aplicación del Análisis de Impacto Regulatorio Ex Ante -en adelante "DS 0632001" o "Reglamento de AIR"—.

Lo más destacable del Reglamento de AIR es que finalmente establece el mandato que obliga a las entidades del Poder Ejecutivo a realizar el AIR previamente a decidir sobre intervenciones reguladoras de carácter general, aunque de manera progresiva. ${ }^{55}$ También corresponde re-

54. Decreto Legislativo 1448:

"Artículo 6.- Diseño de los instrumentos

Mediante decreto supremo refrendado por el Presidente del Consejo de Ministros, el Ministro de Economía y Finanzas y el Ministro de Justicia y Derechos Humanos se aprueba el instrumento referido al análisis de impacto regulatorio." "Segunda Disposición Complementaria Final.-

En un plazo no mayor a 180 días calendario contados a partir del día siguiente de la publicación de la presente norma se aprueba mediante Decreto Supremo refrendado por el Presidente del Consejo de Ministros, el Ministro de Economía y Finanzas y el Ministro de Justicia y Derechos Humanos el instrumento referido al análisis de impacto regulatorio."

55. "Artículo 10.- Ámbito de aplicación del Análisis de Impacto Regulatorio Ex Ante

10.1 La entidad pública del Poder Ejecutivo tiene la obligación de realizar el AIR Ex Ante previo a la elaboración de disposiciones normativas de carácter general, cuando establezcan, incorporen o modifiquen reglas, prohibiciones, limitaciones, obligaciones, condiciones, requisitos, responsabilidades o cualquier exigencia que genere o implique va- 
saltar que en los lineamientos generales se contemplan aspectos relevantes del instrumento de AIR, a saber:

a) Su finalidad: conseguir que la alternativa regulatoria elegida sea la mejor para solucionar el problema público identificado, considerando que sus beneficios son superiores a sus costos. ${ }^{56}$

b) Sus componentes: (i) magnitud y diagnóstico del problema e identificación de los afectados; (ii) desarrollo del objetivo de la intervención; (iii) identificación de las alternativas de solución regulatorias o no regulatorias; (iv) evaluación de los impactos de cada alternativa, para elegir la mejor; (v) descripción y desarrollo de mecanismos de implementación y cumplimiento; (vi) criterios y mecanismos de monitoreo, supervisión y evaluación del cumplimiento. ${ }^{57}$

c) Las obligaciones de las entidades públicas asociadas con el AIR: (i) publicar el primer mes de cada año su "agenda temprana" de problemas públicos que se pretende someter al AIR durante el año y las fechas tentativas; y (ii) realizar dos consultas públicas relacionadas al proceso de elaboración del AIR, una temprana que es previa al diseño del proyecto regulatorio, y otra del proyecto regulatorio para recabar comentarios y opiniones. ${ }^{58}$

d) Las instancias responsables: (i) se establece que los Ministros, los Viceministros y los Secretarios generales son responsables de la conducción de los AIRs de sus respectivos sectores; (ii) se señala a la Comisión Multisectorial de Calidad Regulatoria CMCR - como ente rector del sistema de AIR, y se define su conformación y sistema de votación, así como sus funciones; (iii) se establece la Secretaría Técnica y los equipos técnicos especializados como niveles de soporte de la CMCR; (iv) se prevé la conformación de una Comisión Consultiva para la Mejora de la Calidad Regulatoria. ${ }^{59}$

e) Los niveles del estado y supuestos excluidos del AIR: (i) se excluye de su aplicación a los Poderes Judicial y Legislativo, a las empresas públicas bajo el ámbito de FONAFE o de ámbito regional o local, a las empresas privadas que brindan servicios públicos; (ii) también se excluye de su aplicación supuestos como Decretos de Urgencia en materia económica y financiera, disposiciones y procedimientos de naturaleza tributaria, disposiciones relativas

riación de costos en su cumplimiento por parte de las empresas, ciudadanos o sociedad civil que limite el otorgamiento o reconocimiento de derechos para el óptimo desarrollo de actividades económicas y sociales que contribuyan al desarrollo integral, sostenible, y al bienestar social."

"Artículo 31. Progresividad en la aplicación del Análisis de Impacto Regulatorio Ex Ante

31.1 La implementación del AIR Ex Ante en las entidades públicas del Poder Ejecutivo es progresiva. El plan de implementación progresiva contiene como mínimo el fortalecimiento de capacidades, desarrollo de pilotos, la asistencia técnica, desarrollo de los instrumentos complementarios y plazos para el cumplimiento obligatorio del AIR Ex Ante, según lo dispuesto en la Décima Cuarta Disposición Complementaria Final del presente Reglamento."

56. "Artículo 9.- Objetivo del Análisis de Impacto Regulatorio Ex Ante

El AIR Ex Ante tiene como objetivo garantizar que la propuesta de decisión regulatoria que plantea la entidad pública como resultado del análisis correspondiente, sea la mejor opción para contribuir a solucionar o reducir los riesgos de un problema público identificado en base a evidencia; así como determinar que sus beneficios son superiores a sus costos (...)."

57. Descritos en el artículo 11 del Decreto Supremo Nº63-2021-PCM.

58. Artículos 13 y 14 del Decreto Supremo № 063-2021-PCM.

59. Artículos 17, 19 al 24 y Décima Disposición Complementaria Final del Decreto Supremo № 063-2021-PCM. 
a programas sociales en tanto se regulan por las normas de la materia, resoluciones de procedimientos sancionadores, trilaterales, de solución de controversias, o de fiscalización, designación de funcionarios o cargos de confianza, declaraciones de interés nacional que no generen efectos a terceros, etcétera. ${ }^{60}$

Sin perjuicio de lo anterior, podría discutirse si esta norma ha aprobado el instrumento de AIR, como estaba dispuesto por el DL 1448, pues no contiene el desarrollo específico de las reglas de fondo para que las entidades públicas conduzcan los AIRs, ni para que la CMCR evalúe y apruebe el documento que los contiene. Más bien, se ha delegado en la PCM para que mediante Resolución Ministerial apruebe las reglas medulares para elaborar y revisar los AIRs.

Así, las principales reglas para la implementación efectiva del AIR se han dejado para una etapa posterior, en plazos que oscilan entre un mes a seis meses adicionales. En particular, se ha programado la publicación de las siguientes normas en los plazos indicados, computados a partir del 3 de abril de 2021, fecha de publicación del DS 063-2021:

(i) Reglamento Interno de la CMCR, en 20 días -es decir, hasta el 30 de abril de 2021—;

(ii) Plan para la implementación progresiva del AIR, en 30 días —es decir, hasta el 14 de mayo de 2021-;

(iii) Manual para la aplicación del AIR por las entidades públicas, Metodologías para evaluar impactos del AIR - costo-beneficio, costo-efectividad, multicriterio, etcétera-, y Lineamientos para la Agenda Temprana y la Consulta Pública, todas en
90 días - es decir, hasta el 11 de agosto de 2021-;y

(iv) Manual del evaluador -CMCR - del AIR, en 120 días - es decir, hasta el 23 de septiembre de 2021-.

Lamentablemente, no puede descartarse que tales plazos se dilaten por una u otra razón, haciendo una vez más inefectivo el sistema de AIR por lapsos difíciles de predecir, en particular cuando no se tiene los Manuales, las metodologías de evaluación de impactos y los lineamientos. Téngase en cuenta que el DS 063-2021 no se emitió dentro de los 6 meses previstos en el DL 1448 , sino dos años y medio después..$^{61}$ Algo similar puede ocurrir con las normas antes indicadas, pues a la fecha de envío de este artículo para revisión y publicación, ya se han vencido los plazos programados para emitir las dos primeras normas, es decir, ya están retrasados el Reglamento Interno de la CMCR y el Plan para la implementación progresiva del AIR listadas.

Adicionalmente, debe tenerse en cuenta que esas reglas medulares para el AIR serán aprobadas mediante normas de menor jerarquía. Si bien esto puede contribuir a darle mayor flexibilidad al sistema, permitiendo adecuar más fácil y oportunamente los aspectos que así lo requieran, también puede contribuir a restarle predictibilidad de cara a los ciudadanos. Así, definiciones y conceptos clave para determinar el enfoque del AIR podrían ser modificados sin mucha dificultad, dando lugar, por ejemplo, a una visión reguladora más intervencionista respecto de la libre determinación de los privados.

Algunos aspectos importantes pero ausentes en el DS 063-2021 permiten explicar este punto. Giran en torno a una regla fundamental de todo sistema de AIR y es que ante el problema público

60. Artículos 10.5 y 28 del Decreto Supremo № 063-2021-PCM.

61. Llama la atención el extenso retraso en la emisión del Reglamento de AIR, si se contrasta con los plazos de emisión de los reglamentos para el ACR. En efecto, tanto el Reglamento del Decreto Legislativo 1310, aprobado mediante Decreto Supremo N 075-2017-PCM, como el Reglamento de las disposiciones sobre ACR contenidas en el Decreto Legislativo 1448, aprobado mediante Decreto Supremo N 061-2019-PCM, fueron publicados aproximadamente en seis meses y medio después de las mencionadas leyes. 
identificado siempre se debe considerar dentro de las posibles alternativas una de no intervenir con nueva regulación; es decir, de mantener la situación en el estado en que se encuentra. Esto se conoce como el escenario base.

Aun cuando a primera vista el escenario base pudiera parecer contradictorio con el objetivo mismo del AIR, que es identificar la mejor alternativa regulatoria para solucionar el problema público, en realidad es un referente comparativo necesario para evitar el fallo regulatorio de adoptar una alternativa de intervención que a la larga es peor que haber mantenido el estatus quo. ${ }^{62}$ En efecto, en la etapa de comparación de los costos y beneficios de las alternativas de regulación puede resultar que en términos netos todas ellas ocasionen más impactos negativos que positivos. Ante esa disyuntiva, el escenario base permite mantener el estatus quo pese a sus efectos negativos, pues comparativamente puede ser mejor que adoptar cualquier alternativa de intervención reguladora. ${ }^{63}$

El Reglamento de AIR aprobado debió establecer de modo explícito no solo que dentro de la evaluación se considere la opción de no regular, sino incluso señalar directamente que en caso de duda se debe optar por no regular. Si se piensa que sería atípico, basta señalar que esta regla existe inalterada hace décadas en los $\mathrm{Re}$ glamentos Generales de los organismos regula- dores de servicios públicos peruanos. Solo para muestra se cita a continuación el Reglamento General del OSINERGMIN, aprobado mediante Decreto Supremo No 054-2001-PCM:

\section{"Artículo 11.- Principio de Subsidiariedad La actuación de OSINERG es subsidiaria y ADMINISTRATIVO} sólo procede en aquellos supuestos en los que el mercado y los mecanismos de libre competencia no sean adecuados para la satisfacción de los intereses de los usuarios de servicio público o consumidores regulados. En caso de duda sobre la necesidad de establecer disposiciones regulatorias y/o normativas, se optará por no aprobarlas, y entre varias opciones similarmente efectivas, se optará por la que menos afecte la autonomía privada" — subrayado añadido-.

En vez de contemplar una regla expresa y precisa al respecto, en el Reglamento de AIR se incluyen disposiciones confusas, o con insuficiente desarrollo, que no permiten tener la certeza de que el escenario base no solo es plausible, sino aconsejable en caso de duda. De hecho, al describirse los componentes del AIR, en el artículo 11.1.3 no se precisa que el escenario base debe estar dentro de las alternativas, sino que se utiliza una fórmula poco precisa: "3. Identificación y desarrollo de las alternativas regulatorias o no regulatorias". No existe definición alguna de lo que significa una alternativa no regulatoria.

62. Al respecto, uno de los forjadores del AIR en la OCDE ha señalado:

"El escenario base tiene por finalidad proporcionar el contra factual frente al que se comparan todos los demás escenarios. Es necesario porque la medición de los impactos en el Al [análisis de impacto] es una medida marginal, es decir, el Al muestra las diferencias en los impactos del escenario base y el escenario que se analiza. Sin un escenario base claro, los impactos marginales de los otros escenarios tampoco son claros y no se pueden comparar. (...). El escenario base también suele descuidarse, ya que los reguladores normalmente no han identificado el problema lo suficientemente claro como para permitirles elegir una métrica de medición que les permita evaluar tendencias pasadas o realizar proyecciones. Tampoco tienen suficientes datos para cuantificar el problema o establecer una línea de tendencia. Esto es desafortunado, porque en la definición del escenario base es donde los reguladores se hacen responsables por la definición del problema que identificaron". Jacobs (2016). "Towards a simpler and Practical Approach", 83 (traducción libre).

63. Asumiendo que el problema público identificado tiene impactos negativos de $S / 80$ millones al año y se identifican dos alternativas regulatorias de solución: la alternativa A tiene un costo de S/ 84 millones y la B uno de S/ 69 millones, pero con probabilidad media-alta de ocasionar impactos negativos adicionales de $\mathrm{S} / 18$ millones por posibles comportamientos de cumplimiento creativo - "creative compliance" —. En esta situación, el escenario base resultaría mejor que cualquiera de las dos alternativas reguladoras, es decir, sería preferible mantener el status quo con sus efectos negativos, en vez de asumir el riesgo de errar con la alternativa regulatoria B que podría arrojar un costo adicional neto de S/ 7 millones. 
Podría entenderse que el término se refiere a la opción de no regular, pero no es un vocablo unívoco, así que también podría asumirse, por ejemplo, que se trata de opciones de auto regulación. Para mayor enredo, en el artículo 11.4 se señala que si de la evaluación de alternativas "la entidad pública selecciona una opción no regulatoria como la mejor alternativa (...) procede con su desarrollo e implementación en el marco de sus competencias". Si la alternativa no regulatoria fuera el escenario base, entonces ipor qué la entidad procedería con su desarrollo e implementación, si precisamente implica no intervención reguladora?

Adicionalmente, en el artículo 14.1 que contiene las modalidades de consulta pública, tampoco se explicita que deba considerarse el escenario base. En el caso de la consulta pública temprana se señala que se realiza "en la etapa previa al diseño del proyecto regulatorio", y que comprende la participación de posibles afectados, "el análisis de las alternativas de solución y sus respectivos impactos". Lo razonable sería entender que entre esas alternativas se incluye el escenario base, aunque esto no es explícito.

De otro lado, en la etapa de consulta pública del proyecto regulatorio, parece asumirse que la propuesta ya está en elaboración, y por ello el objeto de esta consulta es "recabar información adicional relevante (...) que permita perfeccionar el proyecto regulatorio, detectar riesgos en el cumplimiento o la implementación y viabilizar la posible intervención (...)". Es decir, pareciera que en esta etapa ya no hay espacio para preferir el escenario base y solo se puede perfeccionar el proyecto de regulación y detectar riesgos vinculados al mismo.

Dicho lo anterior, es evidente que sería preferible que las reglas asociadas con la alternativa de no regular y el escenario base de cualquier sistema de AIR hayan sido plasmadas en una norma con rango de ley, para darle plena legitimidad y respaldo a aquellas entidades públicas que no recurran a la intervención reguladora en caso de duda razonable sobre sus ventajas. De esta forma se enfatizaría que el AIR puede admitir fallas de mercado - escenario base- en vez de apostar por fallas de la regulación que pese a ser bienintencionadas puedan resultar más costosas en términos netos.

El problema en el caso peruano es que esas reglas fundamentales no se han plasmado en una ley y ni siquiera en la norma reglamentaria de mayor rango. En el mejor de los casos, podrían incorporarse en alguno de los manuales o metodologías que serán aprobadas por Resolución Ministerial de PCM. Pero al encontrarse en una norma de esta jerarquía, no sería difícil restringir sus alcances o prescindir de ellas, por ejemplo, si se deseara inclinar la balanza del AIR hacia la intervención reguladora.

De este modo, las reglas para hacer efectivo el AIR no solo vienen bastante demoradas y pueden seguir tardándose, sino que, además, podrán ser modificadas o relativizadas sin mayor dificultad según decisión del Ejecutivo, dada la jerarquía de las normas que las desarrollarán.

\section{UNA OPORTUNIDAD PERDIDA Y UNA RE- FORMA REGULATORIA AÚN INCOMPLETA}

Todo lo expresado hasta aquí demuestra que al finalizar el año 2016 se tuvo en Perú la oportunidad de establecer con rango legal una reforma regulatoria completa, que se sustentara en el AIR como sistema principal, complementado con una simplificación administrativa más sofisticada a través del Modelo Costo Estándar. Ello sin perjuicio de implementar sus componentes de forma progresiva.

Sin embargo, con el DL 1310 se escogió solo una simplificación administrativa más sofisticada, dándole el llamativo nombre de ACR, y dejando para otro momento un componente central como es el AIR. Se perdió una oportunidad de tener un "paquete premium" en materia de reforma regulatoria, y se tomó únicamente un "paquete básico".

En el 2018 se tuvo la oportunidad de enmendar lo anterior a través del DL 1448, pero en vez de hacerlo se decidió solamente modificar el DL 1310 para precisar que con el sistema de ACR solo se buscaba mayor simplificación adminis- 
trativa y no el análisis del impacto de las regulaciones sustantivas. Como premio consuelo, a través de esa misma norma legal se enunció el proceso de mejora de la calidad regulatoria y se incluyó como uno de sus instrumentos el $A I R$, sin contemplar un mandato de rango legal para su implementación, es decir sin ponerle "dientes" al instrumento. Más bien, se contempló que sea una norma reglamentaria la que se ocupe del componente principal de la reforma regulatoria peruana.

Con prolongado retraso, luego de dos años y medio, se aprobó el mencionado Reglamento de AIR. Esta norma contiene el mandato para que las entidades del Poder Ejecutivo realicen obligatoriamente el AIR de sus propuestas normativas de carácter general, aunque de modo progresivo. Asimismo, se incluyó otros elementos relevantes del sistema como la finalidad del AIR, los componentes del proceso de elaboración y validación, la obligación de publicar cada año una agenda temprana de iniciativas regulatorias y de realizar consultas públicas para cada iniciativa, las instancias responsables de conducir y evaluar los AIRs, los ámbitos que sujetos al AIR — niveles del estado y supuestos excluidos-, entre otros.
Sin perjuicio de ello, se trata solo de una norma de lineamientos generales para la aplicación del AIR, no del desarrollo específico de las reglas de fondo para que las entidades públicas conduzcan los AIRs, ni para que la CMCR evalúe y apruebe el documento que los contiene. En el Reglamento de AIR se ha previsto más bien que las reglas necesarias para la implementación efectiva del AIR sean aprobadas vía Resolución Ministerial de la PCM, dentro de un cronograma que va de un mes a seis meses adicionales, con el consiguiente riesgo de que esos plazos se dilaten haciendo inefectivo el sistema de AIR por lapsos que pueden resultar bastante largos.

Adicionalmente, tratándose de reglas medulares para el funcionamiento del AIR, es discutible la ventaja de que sean aprobadas mediante normas de menor jerarquía, ya que podrían ser modificadas sin mayor dificultad, lo que puede restarle predictibilidad de cara a los ciudadanos.

De este modo, el Perú continúa teniendo una reforma regulatoria incompleta, vulnerable, y todavía concentrada en la simplificación administrativa. 